\title{
Extending the CLAST sequential rule to one-way ANOVA under group sampling
}

\author{
Carmen Ximénez and JaVier ReVuelta \\ Universidad Autónoma de Madrid, Madrid, Spain
}

\begin{abstract}
Several studies have demonstrated that the fixed-sample stopping rule (FSR), in which the sample size is determined in advance, is less practical and efficient than are sequential-stopping rules. The composite limited adaptive sequential test (CLAST) is one such sequential-stopping rule. Previous research has shown that CLAST is more efficient in terms of sample size and power than are the FSR and other sequential rules and that it reflects more realistically the practice of experimental psychology researchers. The CLAST rule has been applied only to the $t$ test of mean differences with two matched samples and to the chi-square independence test for twofold contingency tables. The present work extends previous research on the efficiency of CLAST to multiple group statistical tests. Simulation studies were conducted to test the efficiency of the CLAST rule for the one-way ANOVA for fixed effects models. The ANOVA general test and two linear contrasts of multiple comparisons among treatment means are considered. The article also introduces four rules for allocating $N$ observations to $J$ groups under the general null hypothesis and three allocation rules for the linear contrasts. Results show that the CLAST rule is generally more efficient than the FSR in terms of sample size and power for one-way ANOVA tests. However, the allocation rules vary in their optimality and have a differential impact on sample size and power. Thus, selecting an allocation rule depends on the cost of sampling and the intended precision.
\end{abstract}

In performing research with controlled experiments, an investigator must make a number of decisions pertaining to model design and data analysis. One of the most important ones is to determine the sample size. Experimental researchers usually set the sample size $(N)$ by using the fixed-sample rule (FSR), in which the number of observations is determined in advance. However, several studies have demonstrated that sequential-stopping rules, in which the number of observations is not fixed in advance, are more efficient than the FSR in terms of sample size and power and reflect more realistically the practice of experimental researchers. The sequential-stopping rules allow researchers to test their hypotheses as the data are accumulated, so that decisions can be made as the study progresses, whereas the FSR does not stop early enough either when statistical significance is nearly ensured or when it is unlikely.

The sequential rules were first proposed by Wald (1947), who developed sequential rules in which additional sampling is conditionalized on an analysis of the previous data. That is, a hypothesis test conducted over the collected data is the basis for deciding whether more observations should be added to the sample or whether the experiment should end and a final decision about the null hypothesis $\left(\mathrm{H}_{0}\right)$ must be made. A general overview of sequential rules in a statistical context can be found in Ghosh and Sen (1991), Siegmund (1985), and Wetherill and Glazebrook (1986). Sequential sampling rules were introduced by Kimball (1950) and Fiske and Jones (1954) in the context of psychological research.

Sequential rules differ in the number of observations that are incorporated into the sample after each analysis (henceforth referred to as $N_{\text {added }}$ ). In the simplest scenario, data are analyzed after incorporating each observation into the sample. Other sequential rules assume that data are incorporated by groups, and the analyses are done over certain proportions of the final sample (e.g., Lan \& DeMets, 1989; P. C. O'Brien \& Fleming, 1979). These rules, generally referred to as group sequential methods, have rarely been used in psychology (Jennison \& Turnbull, 2000). The smaller the expected number of observations in the final sample, the smaller the number of observations that are added at each step of the sequence. For this reason, sequential methods based on adding single observations should be more efficient than group sequential methods, since finer decisions can be made.

Sequential-stopping rules have received little attention in the field of psychology. For this reason, some authors have developed sequential-stopping rules that are simple and easy to implement. Frick (1998) proposed the composite open adaptive sequential test (COAST). Results of simulation studies indicated that COAST requires about 30\% fewer observations than does FSR to achieve the same power. Botella, Ximénez, Revuelta, and Suero (2006) proposed the composite limited adaptive sequential test (CLAST), which is an extension of COAST. Pre-

C. Ximénez, carmen.ximenez@uam.es 
vious research has shown that CLAST is more efficient, in terms of sample size and power, than is COAST and that it reflects more realistically the practice of experimental researchers, who obviously are not willing to incorporate an unlimited number of observations into their samples. The CLAST rule has been applied only to the one-tailed $t$ test of mean differences with two matched samples and to the chi-square independence test for twofold contingency tables (Botella et al., 2006). The present work extends previous study on the efficiency of CLAST to multiple group statistical tests.

The purpose of this article is to examine the efficiency of the CLAST rule for one-way ANOVA tests. Using simulated data with fixed effects models and six different rules for allocating $N$ observations to $J$ groups (or treatments), the efficiency of the CLAST sequential rule is shown. The remainder of the article is divided into five sections. First, we will explain the general linear model and oneway ANOVA. Second, we will expose the CLAST rule's main characteristics and its use in the context of one-way ANOVA $F$ tests. Third, we will describe the main characteristics of the Monte Carlo study design. Fourth, we will present the results of the simulation study. And fifth, a discussion of the efficiency of the CLAST rule in one-way ANOVA tests will be provided.

\section{THE GENERAL LINEAR MODEL AND ONE-WAY ANOVA}

The ANOVA has long enjoyed the status of being the most used statistical technique in psychological research. The popularity of this technique can be attributed to two main reasons. First, like the $t$ test, it deals with differences between and among sample means; however, it imposes no restrictions on the number of means. Second, the ANOVA allows dealing with two or more independent variables simultaneously, and it provides information not only of each variable effect, but also of the interacting effects of two or more variables (Edwards, 1993). This article focuses on the one-way ANOVA - that is, an analysis of results employing only one independent variable.

The ANOVA is a special case of the general linear model (R. G. O’Brien \& Muller, 1993), which is given by

$$
\boldsymbol{y}=\boldsymbol{X} \boldsymbol{\beta}+\boldsymbol{e},
$$

where $\boldsymbol{y}$ is the $N \times 1$ vector of observations in the dependent variable, $\boldsymbol{X}$ is a $N \times J$ matrix of known predictor values (fixed effects model), $\boldsymbol{\beta}$ is a $J \times 1$ vector of coefficients (parameters), and $\boldsymbol{e}$ is the vector of errors. In an ANOVA, $\boldsymbol{X}$ is a design matrix that allocates observations into groups.

For instance, the vector $\beta$ for an ANOVA with $J=4$ groups is given by

$$
\boldsymbol{\beta}=\left(\mu_{1}, \mu_{2}, \mu_{3}, \mu_{4}\right)^{\prime},
$$

where $\mu_{1}, \mu_{2}, \mu_{3}$, and $\mu_{4}$ are the means of the groups. Suppose that the design matrix for this example is

$$
\boldsymbol{X}=\left(\begin{array}{cccc}
1 & 0 & 0 & 0 \\
0 & 1 & 0 & 0 \\
0 & 0 & 1 & 0 \\
\vdots & \vdots & \vdots & \vdots \\
0 & 0 & 0 & 1
\end{array}\right) .
$$

In this example, the first observation belongs to Group 1, the second observation to Group 2, the third observation to Group 3, and the $n$th observation to Group 4. Then, the rows of $\boldsymbol{X}$ indicate the group for each observation. In consequence, the statistical model for a one-way ANOVA can be written as

$$
Y_{i j}=\mu_{j}+e_{i j},
$$

where $Y_{i j}$ is the observation of the $i$ th subject in the $j$ th treatment and $e_{i j}$ is the error associated with the $i$ th subject in the $j$ th treatment. By assumption, $\mathrm{E}\left(e_{i j}\right)=0$, and the error variance is $\operatorname{Var}\left(e_{i j}\right)=\sigma^{2}$ for any $i$ and $j$. Therefore, the grand mean is

$$
\mu=\sum_{j} \mu_{j} / J
$$

In statistical hypothesis testing under the ANOVA model, the null hypothesis takes the form $\mathrm{H}_{0}: \boldsymbol{C} \boldsymbol{\beta}=\boldsymbol{\theta}$, where $\boldsymbol{C}$ is a matrix of order $d f_{\mathrm{H}} \times J$. The degrees of freedom of $\mathrm{H}_{0}$ are $d f_{\mathrm{H}}=\operatorname{rank}(\boldsymbol{C})$, and $\boldsymbol{\theta}$ is a vector of constants.

In this article, two kinds of hypotheses are tested.

1 . The first is the general null hypothesis of no treatment mean difference or no factor effect (that is, $\mu_{j}=\mu$ for any $j$ ). This hypothesis uses $\theta=0$, and if $J=4$, matrix $C$ is

$$
\boldsymbol{C}=\left(\begin{array}{cccc}
1 & -1 & 0 & 0 \\
1 & 0 & -1 & 0 \\
1 & 0 & 0 & -1
\end{array}\right) .
$$

The value of $d f_{\mathrm{H}}$ for the general null hypothesis is $d f_{\mathrm{H}}=$ $\operatorname{rank}(\boldsymbol{C})=J-1$. In this example, $d f_{\mathrm{H}}=3$.

2. Linear contrasts of multiple comparisons among treatment means are used to test a specific effect among the means. For instance, if $J=4$, the null hypothesis of no linear effect is based on $\boldsymbol{C}=(-3,-1,1,3)$, and the hypothesis that $\mu_{1}=\left(\mu_{2}+\mu_{3}+\mu_{4}\right) / 3$ uses $\boldsymbol{C}=(-3,1,1,1)$. The value of $d f_{\mathrm{H}}$ for these two linear contrasts is $\operatorname{rank}(\boldsymbol{C})=1$.

Under the FSR, Hypotheses 1 and 2 can be tested using the $F$ statistic (R. G. O'Brien \& Muller, 1993). The form of $F$ for the general null hypothesis is given by

$$
F=\frac{N \sum_{j=1}^{J} \omega_{j}\left(\bar{Y}_{j}-\bar{Y}\right)^{2}}{S_{Y}^{2}(J-1)},
$$

where $\bar{Y}_{j}$ is the sample mean for group $j, \omega_{j}$ is the proportion of observations in group $j, \bar{Y}$ is the grand sample mean 


$$
\bar{Y}=\sum_{j} \varpi_{j} \bar{Y}_{j},
$$

and $S_{Y}^{2}$ is the estimate of the error variance

$$
S_{Y}^{2}=\sum_{j} S_{j}^{2},
$$

and $S_{j}^{2}$ is the variance estimate for group $j$. Under $\mathrm{H}_{0}$, the distribution of the $F$ statistic is $F\left(d f_{\mathrm{H}}, J-1\right)$. When $\mathrm{H}_{0}$ is false, $F$ follows a noncentral $F$ distribution, denoted by $F\left(d f_{\mathrm{H}}, J-1, \delta\right)$. The noncentrality parameter is given by $\delta=N v$, where $v$ is computed as follows:

$$
v=\frac{\sum_{j=1}^{J} \varpi_{j}\left(\mu_{j}-\mu\right)^{2}}{\sigma^{2}} .
$$

When $\delta=0$, distribution $F\left(d f_{\mathrm{H}}, J-1, \delta\right)$ is the same as the central $F$ distribution $F\left(d f_{\mathrm{H}}, J-1\right)$. The form of $F$ for linear contrasts is given by

$$
F=\frac{N\left(\sum_{j=1}^{J} c_{j} \bar{Y}_{j}\right)^{2}}{S_{Y}^{2} \sum_{j=1}^{J} \frac{c_{j}^{2}}{\bar{\varpi}_{j}}},
$$

where $c_{j}$ is the $j$ th element of vector $\boldsymbol{C}$. The distribution of $F$ is $F\left(d f_{\mathrm{H}}, J-1, \delta\right)$, the noncentrality parameter is $\delta=$ $N v$, and $v$ is given by

$$
v=\frac{\left(\sum_{j=1}^{J} c_{j} \mu_{j}\right)^{2}}{\sigma^{2} \sum_{j=1}^{J} \frac{c_{j}^{2}}{\varpi_{j}}} .
$$

The distribution of the $F$ statistic described so far is valid only under the FSR. When data are sampled from a sequential process, these distributions are no longer valid. The distribution of the $F$ statistic under sequential sampling has been described in the statistical literature (Jennison \& Turnbull, 2000; Johnson, 1953; Ray, 1956). However, despite the clear advantages of sequential-stopping rules, they have not been used very often in the field of psychology. Increased mathematical sophistication is one reason that has limited their use, although there are a number of others. The tables for applying these procedures cover only a limited number of applied situations; moreover, these procedures require testing against a simple alternative hypothesis.

For these reasons, in this article, we will propose a simple and easy-to-use rule, referred to as CLAST, for conducting sequential analysis under the ANOVA $F$ statistic. Applying CLAST requires only the computation of the $F$ statistic and its $p$ value (these tasks are implemented in any general statistical software package). No other statistical formulas or tables are needed.

CLAST cannot provide exact values for the probabilities of Type I and Type II errors involved in statistical hypothesis testing, as given by the exact formulas described in the literature. However, CLAST provides an approximation for these two error probabilities that is accurate enough for most practical purposes.

\section{THE CLAST RULE IN A ONE-WAY ANOVA}

This section will describe how to apply the CLAST rule to one-way ANOVA tests for fixed effects models. CLAST was developed in the context of the $t$ test for paired comparisons and the $\chi^{2}$ test of independence (see Botella et al., 2006). In contrast, the one-way ANOVA presents the additional difficulty of how to allocate the observations to the groups. We will describe the CLAST rule first and then the allocation rules.

\section{The CLAST Rule}

Under the CLAST rule, the distribution of the test statistic is divided into three zones - significant (S), uncertain (U), and nonsignificant (NS) - according to the values of $\alpha_{1}$ and $\alpha_{\mathrm{u}}$. The value $\alpha_{1}$ is the probability of $\mathrm{S}$, and the value of $\alpha_{\mathrm{u}}$ is the probability of $\mathrm{S}+\mathrm{U}$. This is in contrast to traditional hypothesis testing, where the distribution of the test statistic is divided only in two zones: S and NS.

CLAST consists of the following steps.

1 . Set the sample size needed for the experiment according to the fixed-sample rule (henceforth referred to as $N_{\mathrm{FSR}}$ ). The value of $N_{\mathrm{FSR}}$ depends on the intended power and should be an even number and a multiple of $J$ for the present purposes.

2. Set the initial sample size $(N 1)$ and the maximum sample size for each group $\left(N_{\text {max }}\right)$ as $\pm 50 \%$ of $N_{\mathrm{FSR}} / J$, being $N 1=\left(.5 N_{\mathrm{FSR}}\right) / J$ and $N_{\max }=\left(1.5 N_{\mathrm{FSR}}\right) / J$.

3 . Set the $\alpha$ values which limit the uncertainty region $\left(\alpha_{1}\right.$ and $\left.\alpha_{\mathrm{u}}\right)$ and the intended general significance level $\left(\alpha_{\mathrm{i}}\right)$.

4. Run the experiment assigning $N 1$ observations to each of the $J$ groups.

5. Analyze the data, compute $F$ and the $p$ value. If maximum sample size $\left(N_{\max }\right)$ has been achieved for all groups, go to Step 7; otherwise, go to Step 6.

6. Classify $F$ into one of the following three categories as a function of the $p$ value:
(S) significant,
if $p \leq \alpha_{1}$,
(U) uncertain,
if $\alpha_{1}<p \leq \alpha_{\mathrm{u}}$,

or

(NS) nonsignificant, if $p>\alpha_{\mathrm{u}}$.

Proceed as follows on the basis of the obtained $p$ value:

If $\mathrm{S}, \quad$ stop the experiment and reject $\mathrm{H}_{0}$.

If $\mathrm{U}$, incorporate $N_{\text {added }}$ observations to the sample and go back to Step 5. The next two sections below will describe how to distribute the $N_{\text {added }}$ observations into the $J$ groups.

If NS, stop the experiment and do not reject $\mathrm{H}_{0}$.

7. Classify $F$ into one of the following two categories as a function of the $p$ value and the $\alpha_{\mathrm{i}}$ value (where $\alpha_{\mathrm{i}}$ is 
the intended value for the Type I error rate in the whole sequential test):

(S) significant,

$$
\text { if } p \leq \alpha_{\mathrm{i}} \text {. Reject } \mathrm{H}_{0} \text {. }
$$$$
\text { (NS) nonsignificant, if } p>\alpha_{\mathrm{i}} \text {. Do not reject } \mathrm{H}_{0} \text {. }
$$

Stop the experiment.

The $p$ value associated to $F$ is computed in Step 5. It should be noted that this $p$ value is not the true probability for the $F$ statistic (the true probability is unknown). The $p$ value is correct only if the data come from the FSR. The $p$ value is used ad hoc to set up the CLAST rule because it is readily available from any statistical software.

Figure 1 illustrates Step 6. It shows the distribution of the $F$ statistic, which is divided into three zones: $\mathrm{S}, \mathrm{U}$, and NS, according to values of $\alpha_{1}$ and $\alpha_{\mathrm{u}}$. The horizontal axis of Figure 1 shows the values of the $F$ statistic, and the vertical axis is the density function. The probability of the zone $\mathrm{S}$ is $\alpha_{1}$, and the probability of the zones $\mathrm{S}+\mathrm{U}$ is $\alpha_{\mathrm{u}}$.

\section{Rules for Allocating $N_{\text {added }}$ Observations in $J$ Groups Under the ANOVA General Null Hypothesis}

In the simplest case, $N_{\text {added }}$ is equal to 1 . However, adding observations one by one leads to a time-consuming process, because the independent variable has $J \geq 2$ groups. For accelerating the process, under group sequential sampling, $N_{\text {added }}>1$ observations are incorporated into the sample at each stage of the sequential process. The problem is how to allocate the $N_{\text {added }}$ observations to the $J$ groups. Here, we will propose some rules that are based on the formula for computing $\delta$ (see Equation 3).

Rule 1: Power optimizer. The $N_{\text {added }}$ observations go to the group with the largest estimated effect $\left(\bar{Y}_{j}-\bar{Y}\right)^{2}$. The objective is to maximize $\delta$.

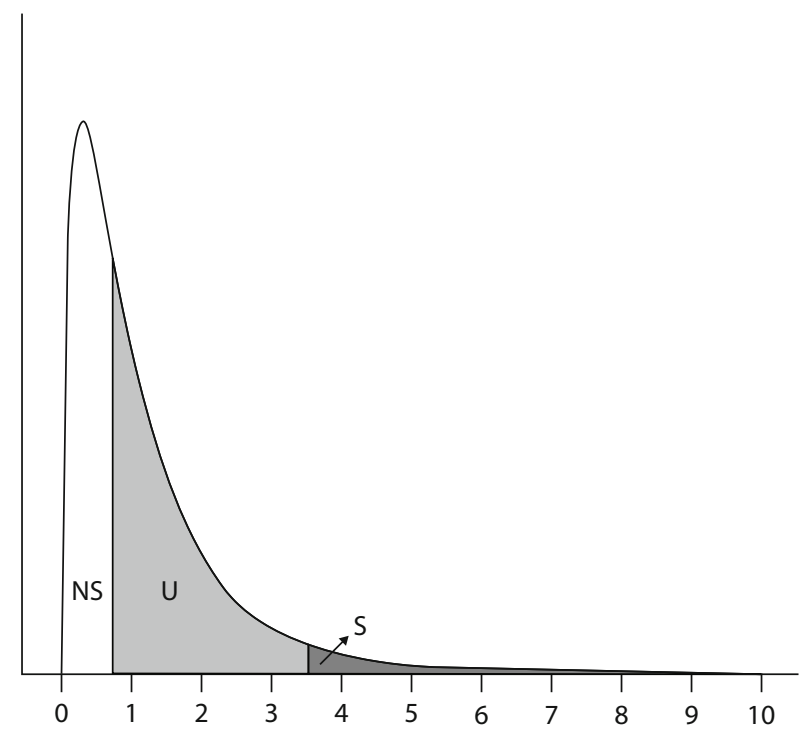

Figure 1. Graphical representation of the CLAST rule for the one-way ANOVA $F$ test with 3 and 12 degrees of freedom. The three decisions are designated by $\mathbf{S}$ (significant), $\mathbf{U}$ (uncertain), and NS (nonsignificant).
Rule 2: Uniform. The same number of observations $\left(N_{\text {added }} / J\right)$ go to each group. This rule is intended to minimize the variance of the estimates of $\mu_{j}$, which is $\sigma^{2} / n_{j}$, where $\sigma$ is the same for all groups and $n_{j}$ is the sample size for each group.

Rule 3: Proportional. The number of observations added to each group $\left(n_{\text {added }}^{(j)}\right)$ is proportional to its estimated effect:

$$
n_{\text {added }}^{(j)}=\frac{N_{\text {added }}\left(\bar{Y}_{j}-\bar{Y}\right)^{2}}{\sum_{j^{\prime}}\left(\bar{Y}_{j^{\prime}}-\bar{Y}\right)^{2}} .
$$

Rule 4: Dropping early. In some applications, the main objective is to find the most different groups, instead of testing the general null hypothesis. In this case, the two groups with the largest absolute difference between their means receive $N_{\text {added }} / 2$ observations. For the other groups, $n_{\text {added }}^{(j)}=0$.

\section{Rules for Allocating $N_{\text {added }}$ Observations Under Linear Contrasts}

As was shown before, the formula for computing $F$ under linear contrasts differs from that for the general null hypothesis. Then, Rules 1, 3, and 4 do not apply under linear contrasts, and Rules 5 and 6 are proposed to maximize the appropriate $\delta$ (see Equation 4).

Rule 5: Uniform by groups. Linear contrasts classify the $J$ means into two classes, one with positive coefficients and another one with negative coefficients. $N_{\text {added }} / 2$ observations go to each of the two classes and are distributed evenly to the groups that form the class.

Rule 6: Proportional to the coefficient values. The number of observations that go to each group is proportional to the absolute value of its coefficient:

$$
n_{\text {added }}^{(j)}=\frac{N_{\text {added }}\left|c_{j}\right|}{\sum_{j^{\prime}}\left|c_{j^{\prime}}\right|} .
$$

\section{MONTE CARLO SIMULATION STUDIES}

We conducted two simulation studies to evaluate the efficiency of the CLAST rule, as compared with the FSR. Study 1 was a simulation intended to determine the optimal values of $\alpha_{\mathrm{u}}$ for each test under study. In Study 2, we kept $\alpha_{\mathrm{u}}$ constant at the value obtained in Study 1 and assessed the efficiency of CLAST in terms of sample size and power, using different sample and effect sizes. Both simulations were conducted separately for the ANOVA general test and for the linear contrasts of multiple comparisons among treatment means.

\section{Method}

The studies were conducted by using Monte Carlo simulations. The programs were written in $\mathrm{R}$ language (Venables \& Smith, 2001), a free distribution version of the well-known S language (Becker, Chambers, \& Wilks, 1988). The simulation consisted of applying the CLAST rule with the following specifications. 
Test statistics. The simulation was run with two different test statistics: the $F$ test for the one-way ANOVA general test for fixed effects models and the $F$ test for linear contrasts of multiple comparisons among treatment means. The $F$ test of the ANOVA general test referred to four treatments. Then, the null hypothesis was $\mathrm{H}_{0}: \mu_{1}=$ $\mu_{2}=\mu_{3}=\mu_{4}$. Two linear contrasts were considered. Linear Contrast 1 compared a group of two means with another group of two means - that is, $\mathrm{H}_{0(\mathrm{LC}) \mathrm{s}}:-3 \mu_{1}-\mu_{2}+$ $\mu_{3}+3 \mu_{4}=0$. Linear Contrast 2 compared a group of one mean with another group of three means - that is, $\mathrm{H}_{0(\mathrm{LC} 2)}$ : $-3 \mu_{1}+\mu_{2}+\mu_{3}+\mu_{4}=0$. The computation of effect size for each test was defined in the General Linear Model and One-Way ANOVA section (see Equations 4 and 5).

Parameters of the simulations. Table 1 summarizes the conditions of the Monte Carlo simulation for Study 1 and Study 2. In Study 1, all treatment means were null, because the $\mathrm{H}_{0}$ to be tested was the equality of means with $\mathrm{H}_{0}$ true. However, in Study 2, we used two different combination values of treatment means $(-.3,-.1, .1, .3$ and $-.6,-.2, .2, .6)$, because the $\mathrm{H}_{0}$ to be tested was that there would not be a linear effect. The value of the error variance in all simulations was 1 . The means and the error variance were settled to provide a range of values from low to high power.

Several aspects of the simulations were common to all the conditions. First, the simulation studies for the ANOVA general test used Rules 1, 2, 3, and 4, whereas the simulation studies for the linear contrasts used Rules 2,5 , and 6 . Second, the values of $N_{\mathrm{FSR}}$ were set from a range frequently employed by experimental psychologists in practice. In both tests, $N_{\mathrm{FSR}}$ equaled 16, 32, 64, and 128. Third, the values of $N 1$ and $N_{\max }$ for each group depended on $N_{\text {FSR }}$. Specifically, $N 1=2,4,8$, or 16 , and $N_{\max }=6$, 12,24 , or 48 . Fourth, $N_{\text {added }}$ was 4,8 , and 12 for all the simulation conditions. As we referred to four groups, observations were added to each group one, two, and three at a time. And fifth, the effect sizes were .05 and .20 for the ANOVA general test, and .05 and .12 for the linear contrasts. We used different effect sizes values for the linear contrasts in order to maintain the power values at rates similar to those in the ANOVA general test. Of course, $\mathrm{H}_{0}$ was true only when $v$ and $\delta$ equaled 0 .

The value of the lower bound $\left(\alpha_{1}\right)$ was .01 , both for the ANOVA general test and for the linear contrasts of multiple comparisons among treatment means. The values of

Table 1

Summary of the Study Conditions for the Monte Carlo Simulation

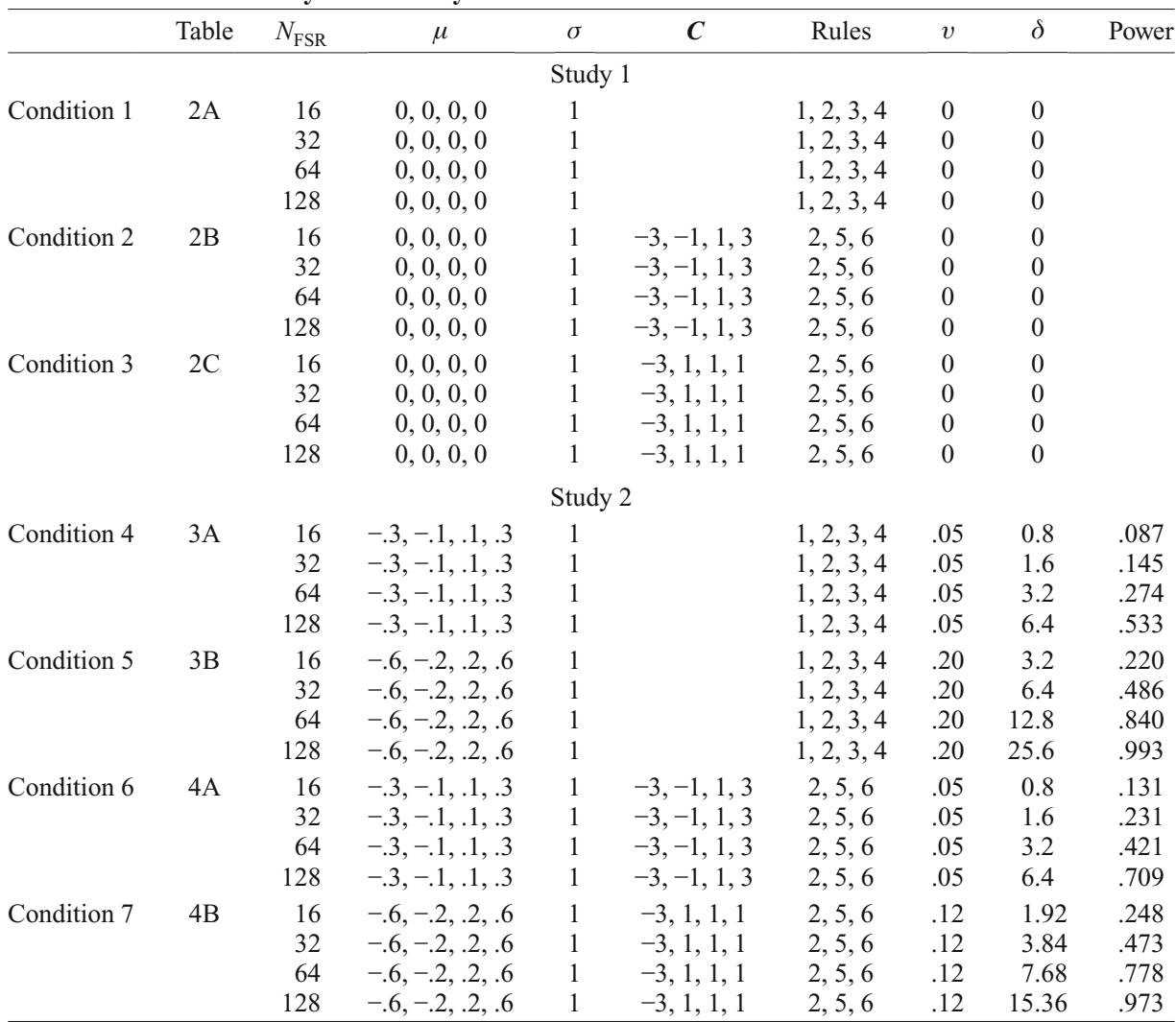

Note- $N_{\mathrm{FSR}}$, total sample size; $n_{j}$, sample size in each treatment; $\boldsymbol{C}$, coefficients for the contrasts (an overall $F$ statistic applies to the conditions with no contrasts); Rules, sequential rules to be applied to each condition; $v$ and $\delta$, effect size measures (described in Equations 3 and 4); Power, power associated to $N_{\mathrm{FSR}} \cdot v, \delta$, and Power correspond to the FSR with $N_{\text {FSR }}$ observations distributed evenly among the groups. "Table" indicates the table where the results for each condition are shown. 
Table 2A

Results of the Simulations for $\mathrm{H}_{0}$ True $(\delta=0)$ and Several Upper Bounds $\left(\alpha_{w}\right)$ of CLAST in the One-Way ANOVA General Test for Each Rule for Allocating $N_{\text {added }}$ Observations in Four Groups

\begin{tabular}{|c|c|c|c|c|c|c|c|c|c|c|}
\hline & $N_{\text {added }}$ & $N 1$ & $N_{\max }$ & $\begin{array}{l}\text { EPR for } \\
\alpha_{u}=.30\end{array}$ & $\begin{array}{l}\text { EPR for } \\
\alpha_{u}=.35\end{array}$ & $\begin{array}{l}\text { EPR for } \\
\alpha_{u}=.40\end{array}$ & $\begin{array}{l}\text { EPR for } \\
\alpha_{u}=.45 \\
\end{array}$ & $\begin{array}{l}\text { EPR for } \\
\alpha_{\mathrm{u}}=.50\end{array}$ & $\begin{array}{l}\text { EPR for } \\
\alpha_{\mathrm{u}}=.55\end{array}$ & $\begin{array}{l}\text { EPR for } \\
\alpha_{u}=.60\end{array}$ \\
\hline \multirow[t]{12}{*}{ Rule 1} & \multirow[t]{4}{*}{4} & 2 & 6 & .041 & .038 & .041 & .041 & .042 & .040 & .043 \\
\hline & & 4 & 12 & .036 & .035 & .038 & .037 & .038 & .036 & .040 \\
\hline & & 8 & 24 & .033 & .037 & .037 & .042 & .043 & .039 & .039 \\
\hline & & 16 & 48 & .030 & .036 & .035 & .039 & .043 & .039 & .041 \\
\hline & \multirow[t]{4}{*}{8} & 2 & 6 & .036 & .041 & .040 & .041 & .042 & .041 & .043 \\
\hline & & 4 & 12 & .035 & .037 & .041 & .038 & .040 & .037 & .040 \\
\hline & & 8 & 24 & .033 & .036 & .033 & .037 & .036 & .040 & .040 \\
\hline & & 16 & 48 & .031 & .033 & .035 & .037 & .036 & .041 & .039 \\
\hline & \multirow{4}{*}{12} & 2 & 6 & .038 & .039 & .035 & .039 & .042 & .041 & .040 \\
\hline & & 4 & 12 & .034 & .037 & .038 & .038 & .041 & .041 & .039 \\
\hline & & 8 & 24 & .033 & .030 & .034 & .033 & .036 & .037 & .036 \\
\hline & & 16 & 48 & .030 & .035 & .032 & .036 & .034 & .039 & .038 \\
\hline MSD & & & & .263 & .197 & .189 & .147 & .125 & .119 & .108 \\
\hline \multirow[t]{12}{*}{ Rule 2} & \multirow[t]{4}{*}{4} & 2 & 6 & .039 & .048 & .054 & .051 & .055 & .062 & .059 \\
\hline & & 4 & 12 & .042 & .048 & .052 & .056 & .057 & .057 & .062 \\
\hline & & 8 & 24 & .046 & .053 & .052 & .055 & .053 & .059 & .066 \\
\hline & & 16 & 48 & .049 & .051 & .054 & .056 & .061 & .063 & .062 \\
\hline & \multirow[t]{4}{*}{8} & 2 & 6 & .039 & .046 & .045 & .051 & .049 & .060 & .056 \\
\hline & & 4 & 12 & .043 & .047 & .048 & .054 & .049 & .057 & .056 \\
\hline & & 8 & 24 & .042 & .045 & .050 & .054 & .054 & .055 & .056 \\
\hline & & 16 & 48 & .043 & .047 & .052 & .058 & .055 & .062 & .061 \\
\hline & \multirow[t]{4}{*}{12} & 2 & 6 & .037 & .040 & .046 & .048 & .050 & .052 & .053 \\
\hline & & 4 & 12 & .039 & .041 & .049 & .050 & .054 & .056 & .058 \\
\hline & & 8 & 24 & .038 & .043 & .047 & .051 & .050 & .057 & .060 \\
\hline & & 16 & 48 & .046 & .047 & .049 & .051 & .054 & .059 & .064 \\
\hline MSD & & & & .080 & .026 & .009 & .016 & .024 & .075 & .101 \\
\hline \multirow[t]{12}{*}{ Rule 3} & \multirow[t]{4}{*}{4} & 2 & 6 & .033 & .035 & .036 & .036 & .034 & .039 & .045 \\
\hline & & 4 & 12 & .034 & .037 & .040 & .041 & .043 & .039 & .042 \\
\hline & & 8 & 24 & .032 & .039 & .042 & .044 & .041 & .042 & .043 \\
\hline & & 16 & 48 & .032 & .038 & .042 & .039 & .042 & .044 & .044 \\
\hline & \multirow{4}{*}{8} & 2 & 6 & .031 & .034 & .036 & .036 & .037 & .038 & .037 \\
\hline & & 4 & 12 & .031 & .038 & .036 & .037 & .037 & .036 & .039 \\
\hline & & 8 & 24 & .036 & .035 & .035 & .037 & .039 & .041 & .040 \\
\hline & & 16 & 48 & .038 & .040 & .036 & .041 & .041 & .040 & .045 \\
\hline & \multirow[t]{4}{*}{12} & 2 & 6 & .030 & .034 & .032 & .039 & .036 & .039 & .037 \\
\hline & & 4 & 12 & .031 & .034 & .034 & .035 & .042 & .039 & .037 \\
\hline & & 8 & 24 & .034 & .032 & .033 & .035 & .041 & .039 & .039 \\
\hline & & 16 & 48 & .034 & .036 & .038 & .039 & .039 & .039 & .040 \\
\hline MSD & & & & .295 & .202 & .193 & .145 & .124 & .110 & .097 \\
\hline \multirow[t]{12}{*}{ Rule 4} & \multirow[t]{4}{*}{4} & 2 & 6 & .030 & .033 & .036 & .038 & .037 & .039 & .039 \\
\hline & & 4 & 12 & .032 & .032 & .039 & .037 & .042 & .038 & .043 \\
\hline & & 8 & 24 & .033 & .033 & .040 & .037 & .041 & .040 & .042 \\
\hline & & 16 & 48 & .034 & .039 & .040 & .041 & .040 & .045 & .045 \\
\hline & \multirow{4}{*}{8} & 2 & 6 & .027 & .029 & .033 & .029 & .035 & .035 & .032 \\
\hline & & 4 & 12 & .029 & .032 & .030 & .037 & .035 & .038 & .034 \\
\hline & & 8 & 24 & .034 & .032 & .032 & .039 & .040 & .039 & .041 \\
\hline & & 16 & 48 & .030 & .036 & .037 & .037 & .041 & .040 & .037 \\
\hline & \multirow[t]{4}{*}{12} & 2 & 6 & .031 & .033 & .035 & .032 & .036 & .035 & .034 \\
\hline & & 4 & 12 & .030 & .028 & .032 & .035 & .034 & .036 & .036 \\
\hline & & 8 & 24 & .029 & .030 & .036 & .036 & .038 & .034 & .036 \\
\hline & & 16 & 48 & .031 & .038 & .037 & .038 & .035 & .037 & .039 \\
\hline MSD & & & & .375 & .306 & .217 & .197 & .158 & .153 & .159 \\
\hline Total MSD & & & & .253 & .183 & .152 & .127 & .108 & .114 & .116 \\
\hline
\end{tabular}

Note-The mean squared difference (MSD) is 1,000 times the MSD between the empirical proportion of rejections (EPR) and the intended alpha level (.05).

the upper bound $\left(\alpha_{\mathrm{u}}\right)$ that would yield a cumulative Type I error rate as close as possible to .05 were determined in the simulations of Study 1. The results are presented below for each statistical test. The value of $\alpha_{i}$ was .05. The simulation was repeated 10,000 times for each condition.
Data analysis. The data gathered from each condition were the mean and standard deviation of the sample size $(N)$ and the empirical proportion of rejections (EPR) of $\mathrm{H}_{0}$, which, with $\mathrm{H}_{0}$ false, is an estimate of the power of the sequential rule. 
Table 2B

Results of the Simulations for $\mathrm{H}_{0}$ True $(\delta=0)$ and Several Upper Bounds $\left(\alpha_{\mathrm{u}}\right)$ of CLAST in the Linear Contrast 1 for Each Rule for Allocating $N_{\text {added }}$ Observations in Four Groups

\begin{tabular}{|c|c|c|c|c|c|c|c|c|c|c|}
\hline & $N_{\text {added }}$ & $N 1$ & $N_{\max }$ & $\begin{array}{l}\text { EPR for } \\
\alpha_{\mathrm{u}}=.30\end{array}$ & $\begin{array}{l}\text { EPR for } \\
\alpha_{\mathrm{u}}=.35\end{array}$ & $\begin{array}{l}\text { EPR for } \\
\alpha_{\mathrm{u}}=.40\end{array}$ & $\begin{array}{l}\text { EPR for } \\
\alpha_{\mathrm{u}}=.45\end{array}$ & $\begin{array}{l}\text { EPR for } \\
\alpha_{\mathrm{u}}=.50\end{array}$ & $\begin{array}{l}\text { EPR for } \\
\alpha_{\mathrm{u}}=.55\end{array}$ & $\begin{array}{l}\text { EPR for } \\
\alpha_{u}=.60\end{array}$ \\
\hline \multirow[t]{12}{*}{ Rule 2} & \multirow[t]{4}{*}{4} & 2 & 6 & .043 & .047 & .049 & .052 & .055 & .056 & .062 \\
\hline & & 4 & 12 & .042 & .049 & .053 & .053 & .056 & .059 & .056 \\
\hline & & 8 & 24 & .049 & .048 & .049 & .048 & .054 & .055 & .059. \\
\hline & & 16 & 48 & .047 & .050 & .052 & .053 & .056 & .058 & .059 \\
\hline & \multirow[t]{4}{*}{8} & 2 & 6 & .043 & .047 & .051 & .049 & .052 & .052 & .058 \\
\hline & & 4 & 12 & .044 & .047 & .043 & .050 & .052 & .054 & .054 \\
\hline & & 8 & 24 & .041 & .048 & .048 & .048 & .052 & .051 & .056 \\
\hline & & 16 & 48 & .044 & .049 & .049 & .050 & .053. & .057. & .056 \\
\hline & \multirow[t]{4}{*}{12} & 2 & 6 & .041 & .045 & .044 & .051 & .048 & .053 & .056 \\
\hline & & 4 & 12 & .044 & .042 & .046 & .047 & .052 & .051 & .052 \\
\hline & & 8 & 24 & .043 & .049 & .048 & .050 & .050 & .051 & .056 \\
\hline & & 16 & 48 & .045 & .048 & .048 & .050 & .053 & .052 & .059 \\
\hline MSD & & & & .044 & .012 & .011 & .004 & .012 & .024 & .052 \\
\hline \multirow[t]{12}{*}{ Rule 5} & \multirow[t]{4}{*}{4} & 2 & 6 & .043 & .043 & .013 & .051 & .051 & .053 & .053 \\
\hline & & 4 & 12 & .046 & .044 & .011 & .051 & .054 & .047 & .057 \\
\hline & & 8 & 24 & .043 & .048 & .009 & .051 & .052 & .055 & .054 \\
\hline & & 16 & 48 & .044 & .049 & .049 & .055 & .052 & .059. & .059 \\
\hline & \multirow[t]{4}{*}{8} & 2 & 6 & .039 & .042 & .044 & .048 & .051 & .054 & .053 \\
\hline & & 4 & 12 & .038 & .044 & .047 & .046 & .049 & .051 & .052 \\
\hline & & 8 & 24 & .039 & .047 & .048 & .053 & .045 & .050 & .057 \\
\hline & & 16 & 48 & .043 & .047 & .045 & .049 & .051 & .056 & .053 \\
\hline & \multirow[t]{4}{*}{12} & 2 & 6 & .039 & .046 & .044 & .044 & .049 & .047 & .051 \\
\hline & & 4 & 12 & .044 & .041 & .045 & .047 & .045 & .047 & .052 \\
\hline & & 8 & 24 & .042 & .046 & .047 & .045 & .050 & .050 & .055 \\
\hline & & 16 & 48 & .045 & .048 & .048 & .045 & .052 & .052 & .056 \\
\hline MSD & & & & .071 & .029 & .014 & .013 & .007 & .016 & .024 \\
\hline \multirow[t]{12}{*}{ Rule 6} & \multirow[t]{4}{*}{4} & 2 & 6 & .042 & .050 & .052 & .055 & .054 & .055 & .058 \\
\hline & & 4 & 12 & .041 & .047 & .049 & .052 & .051 & .057 & .054 \\
\hline & & 8 & 24 & .045 & .050 & .049 & .051 & .052 & .056 & .055 \\
\hline & & 16 & 48 & .046 & .046 & .052 & .052 & .055 & .056 & .058 \\
\hline & \multirow[t]{4}{*}{8} & 2 & 6 & .043 & .045 & .050 & .046 & .053 & .051 & .054 \\
\hline & & 4 & 12 & .041 & .044 & .046 & .047 & .050 & .051 & .053 \\
\hline & & 8 & 24 & .046 & .046 & .049 & .051 & .052 & .056 & .055 \\
\hline & & 16 & 48 & .044 & .045 & .048 & .053 & .055 & .053 & .056 \\
\hline & \multirow[t]{4}{*}{12} & 2 & 6 & .042 & .043 & .044 & .042 & .051 & .051 & .047 \\
\hline & & 4 & 12 & .043 & .043 & .048 & .046 & .048 & .052 & .050 \\
\hline & & 8 & 24 & .044 & .048 & .049 & .050 & .054 & .053. & .054 \\
\hline & & 16 & 48 & .038 & .043 & .050 & .050 & .055 & .054 & .057 \\
\hline MSD & & & & .056 & .025 & .006 & .011 & .011 & .018 & .026 \\
\hline Total MSD & & & & .057 & .022 & .010 & .009 & .010 & .019 & .034 \\
\hline
\end{tabular}

Note-The mean squared difference (MSD) is 1,000 times the MSD between the empirical proportion of rejections (EPR) and the intended alpha level (.05).

The efficiency of the CLAST rule in terms of sample size was computed by comparing the sample size for the fixed sample rule $\left(N_{\mathrm{FSR}}\right)$ with the sample size needed with the CLAST rule $(N)$, by using the equation

$$
N_{\text {Efficiency }}=\frac{N_{\text {FSR }}-N}{N_{\text {FSR }}} \times 100 .
$$

If $N_{\text {Efficiency }}$ is positive, there is a saving in the number of observations with the CLAST rule.

The efficiency in terms of power consists of computing power under the FSR (which assumes a sample size of $N_{\text {FSR }}$ ). The power estimate of the sequential rule (EPR) can be compared with the power of the FSR by using the equation

$$
P_{\text {Efficiency }}=\frac{\operatorname{Power}\left(N_{\mathrm{FSR}}\right)-\mathrm{EPR}}{\operatorname{Power}\left(N_{\mathrm{FSR}}\right)} \times 100 .
$$

If $P_{\text {Efficiency }}$ is negative, the power of the sequential rule is higher than the corresponding FSR, and the reverse occurs if $P_{\text {Efficiency }}$ is positive.

\section{Results}

Results are presented separately for Studies 1 and 2. Study 1 was intended to determine the upper bound $\left(\alpha_{\mathrm{u}}\right)$ of the uncertainty region that holds the Type I error rate as close as possible to the intended significance level for the one-way ANOVA general test and for the two linear contrasts of multiple comparisons among treatment means $\left(\alpha_{i}=.05\right)$. Study 2 examined the efficiency of CLAST, 
Table 2C

Results of the Simulations for $\mathrm{H}_{0}$ True $(\delta=0)$ and Several Upper Bounds $\left(\alpha_{\mathrm{u}}\right)$ of CLAST in the Linear Contrast 2 for Each Rule for Allocating $N_{\text {added }}$ Observations in Four Groups

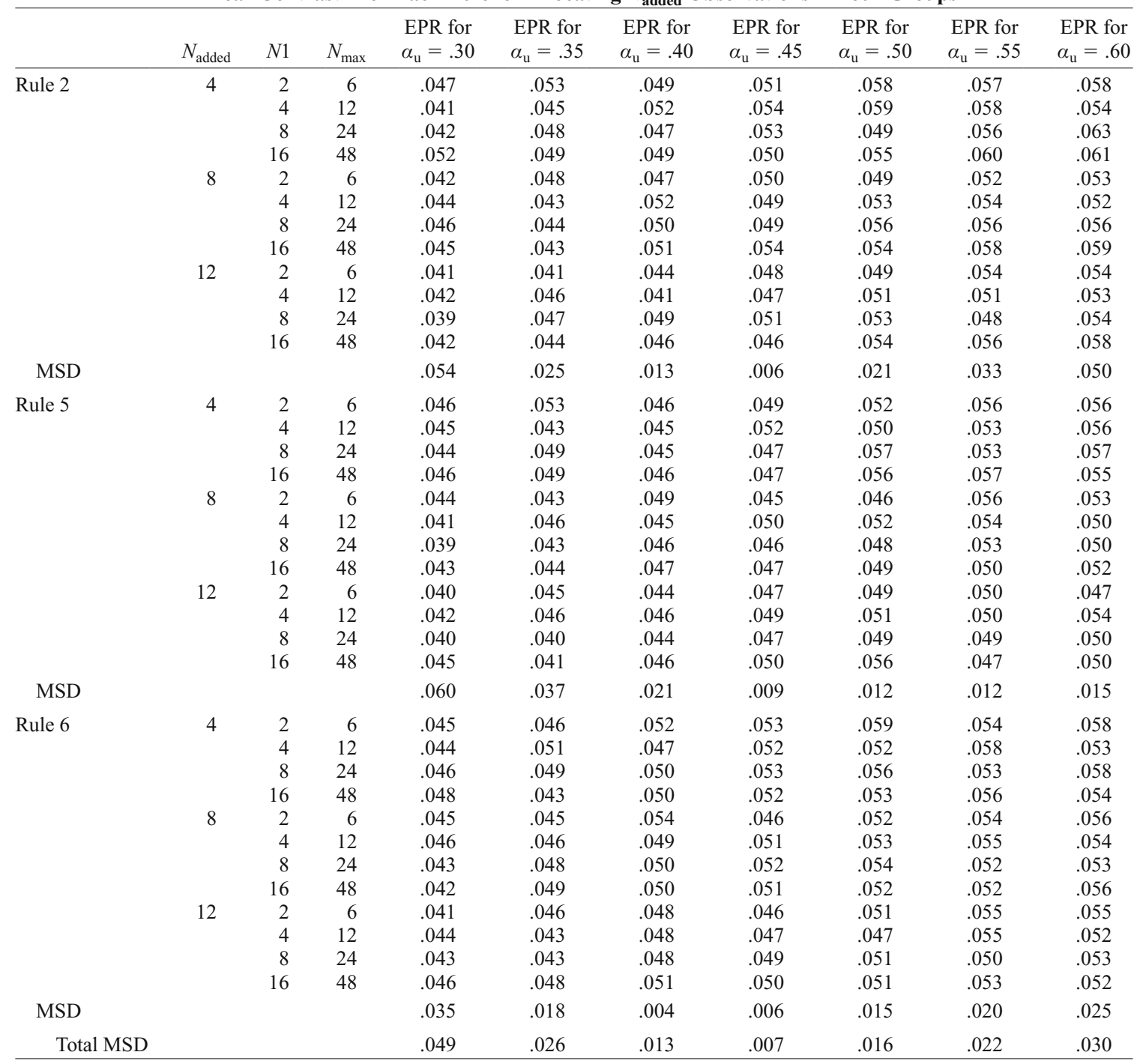

Note-The mean squared difference (MSD) is 1,000 times the MSD between the empirical proportion of rejections (EPR) and the intended alpha level (.05).

as compared with FSR, in terms of sample size and power for all the ANOVA statistical tests under study.

Study 1: Determination of the upper bound of the uncertainty region. Table $2 \mathrm{~A}$ shows the results of the simulations (which assume $\delta=0$ ) for the one-way ANOVA general test. The seven columns named EPR (empirical proportion of rejections of $\mathrm{H}_{0}$ ) represent here an estimate of the Type I error rate. Each EPR column shows the results for a different $\alpha_{\mathrm{u}}$ value referred to each rule for allocating $N_{\text {added }}$ observations to $J$ groups and to each sample size. The rows labeled $M S D$ indicate 1,000 times the mean squared difference between the EPR and the intended alpha level (.05). The upper bound that produces an EPR closest to .05 is indicated by the lowest MSD value at the bottom of the table. As we can see from the last row of Table 2A (Total MSD), the upper bound that produces an EPR closest to .05 is $\alpha_{\mathrm{u}}=.50$. This is, by using the one-way ANOVA general test for fixed effects models and setting a maximum value for $N$ as a stopping criterion, the maximum value of $p$ for continuing to incorporate subjects while maintaining the Type I error rate at a .05 level is .50 .

Tables $2 \mathrm{~B}$ and $2 \mathrm{C}$ include simulations similar to those shown in Table 2A, but for the case of the two linear contrasts of multiple comparisons among treatment means. As can be seen, for Linear Contrast 1, the upper bound that produced cumulative rates closest to .05 was $\alpha_{\mathrm{u}}=$ .45 (see Table 2B).

Table 2C shows that for Linear Contrast 2, the upper bound that produced cumulative rates closest to .05 was also $\alpha_{\mathrm{u}}=.45$. This is, by using linear contrasts of multiple comparisons among treatment means and setting a maxi- 
Table 3A

Results of Simulations of CLAST With $\alpha_{\mathrm{u}}=.50$ and $v=.05$ in the One-Way ANOVA General Test

\begin{tabular}{|c|c|c|c|c|c|c|c|c|c|c|c|c|}
\hline & $N_{\text {added }}$ & $N_{\text {FSR }}$ & $N 1$ & $N_{\max }$ & $\delta$ & $\begin{array}{c}\text { Power of } \\
N_{\text {FSR }}\end{array}$ & $\begin{array}{l}\text { Mean } \\
\text { of } N\end{array}$ & $\begin{array}{l}\text { Standard } \\
\text { Deviation } \\
\text { of } N\end{array}$ & EPR & MSD & $N_{\text {Efficiency }}$ & $P_{\text {Efficiency }}$ \\
\hline \multirow[t]{12}{*}{ Rule 1} & \multirow[t]{4}{*}{4} & 16 & 2 & 6 & 0.8 & .087 & 10.13 & 2.00 & .066 & 0.44 & 36.69 & 24.14 \\
\hline & & 32 & 4 & 12 & 1.6 & .145 & 21.47 & 5.53 & .115 & 0.90 & 32.91 & 20.69 \\
\hline & & 64 & 8 & 24 & 3.2 & .274 & 43.69 & 11.57 & .240 & 1.16 & 31.73 & 12.41 \\
\hline & & 128 & 16 & 48 & 6.4 & .533 & 88.02 & 23.18 & .481 & 2.70 & 31.23 & 9.76 \\
\hline & \multirow[t]{4}{*}{8} & 16 & 2 & 6 & 0.8 & .087 & 10.10 & 2.00 & .067 & 0.40 & 36.88 & 22.99 \\
\hline & & 32 & 4 & 12 & 1.6 & .145 & 20.60 & 3.96 & .097 & 2.30 & 35.62 & 33.10 \\
\hline & & 64 & 8 & 24 & 3.2 & .274 & 44.57 & 11.26 & .225 & 2.40 & 30.36 & 17.88 \\
\hline & & 128 & 16 & 48 & 6.4 & .533 & 89.96 & 22.96 & .486 & 2.21 & 29.72 & 8.82 \\
\hline & \multirow[t]{4}{*}{12} & 16 & 2 & 6 & 0.8 & .087 & 10.11 & 2.00 & .065 & 0.48 & 36.81 & 25.29 \\
\hline & & 32 & 4 & 12 & 1.6 & .145 & 20.59 & 3.96 & .097 & 2.30 & 35.66 & 33.10 \\
\hline & & 64 & 8 & 24 & 3.2 & .274 & 48.36 & 14.47 & .253 & 0.44 & 24.44 & 7.66 \\
\hline & & 128 & 16 & 48 & 6.4 & .533 & 92.89 & 24.13 & .496 & 1.37 & 27.43 & 6.94 \\
\hline Mean values & & & & & & .259 & 41.71 & 10.59 & .224 & 1.43 & 32.46 & 18.57 \\
\hline \multirow[t]{12}{*}{ Rule 2} & \multirow[t]{4}{*}{4} & 16 & 2 & 6 & 0.8 & .087 & 13.94 & 6.75 & .114 & 0.73 & 12.88 & -31.03 \\
\hline & & 32 & 4 & 12 & 1.6 & .145 & 28.07 & 13.56 & .188 & 1.85 & 12.28 & -29.66 \\
\hline & & 64 & 8 & 24 & 3.2 & .274 & 56.63 & 26.54 & .352 & 6.08 & 11.52 & -28.47 \\
\hline & & 128 & 16 & 48 & 6.4 & .533 & 108.97 & 47.94 & .625 & 8.46 & 14.87 & -17.26 \\
\hline & \multirow[t]{4}{*}{8} & 16 & 2 & 6 & 0.8 & .087 & 15.32 & 7.24 & .110 & 0.53 & 4.25 & -26.44 \\
\hline & & 32 & 4 & 12 & 1.6 & .145 & 29.63 & 14.08 & .182 & 1.37 & 7.41 & -25.52 \\
\hline & & 64 & 8 & 24 & 3.2 & .274 & 59.43 & 27.35 & .356 & 6.72 & 7.14 & -29.93 \\
\hline & & 128 & 16 & 48 & 6.4 & .533 & 113.13 & 49.48 & .629 & 9.22 & 11.62 & -18.01 \\
\hline & \multirow[t]{4}{*}{12} & 16 & 2 & 6 & 0.8 & .087 & 15.89 & 7.45 & .107 & 0.40 & 0.69 & -22.99 \\
\hline & & 32 & 4 & 12 & 1.6 & .145 & 31.08 & 14.42 & .190 & 2.03 & 2.88 & -31.03 \\
\hline & & 64 & 8 & 24 & 3.2 & .274 & 62.04 & 27.81 & .355 & 6.56 & 3.06 & -29.56 \\
\hline & & 128 & 16 & 48 & 6.4 & .533 & 116.85 & 50.24 & .630 & 9.41 & 8.71 & -18.20 \\
\hline Mean values & & & & & & .259 & 54.25 & 24.40 & .320 & 4.45 & 8.11 & -25.67 \\
\hline \multirow[t]{12}{*}{ Rule 3} & \multirow[t]{4}{*}{4} & 16 & 2 & 6 & 0.8 & .087 & 11.43 & 3.72 & .075 & 0.14 & 28.56 & 13.79 \\
\hline & & 32 & 4 & 12 & 1.6 & .145 & 22.72 & 7.29 & .131 & 0.20 & 29.00 & 9.66 \\
\hline & & 64 & 8 & 24 & 3.2 & .274 & 45.89 & 14.34 & .265 & 0.08 & 28.30 & 3.28 \\
\hline & & 128 & 16 & 48 & 6.4 & .533 & 91.44 & 27.35 & .519 & 0.20 & 28.56 & 2.63 \\
\hline & \multirow[t]{4}{*}{8} & 16 & 2 & 6 & 0.8 & .087 & 12.03 & 4.04 & .074 & 0.17 & 24.81 & 14.94 \\
\hline & & 32 & 4 & 12 & 1.6 & .145 & 24.19 & 7.98 & .130 & 0.22 & 24.41 & 10.34 \\
\hline & & 64 & 8 & 24 & 3.2 & .274 & 48.89 & 15.62 & .275 & 0.00 & 23.61 & -0.36 \\
\hline & & 128 & 16 & 48 & 6.4 & .533 & 94.97 & 29.04 & .534 & 0.00 & 25.80 & -0.19 \\
\hline & \multirow{4}{*}{12} & 16 & 2 & 6 & 0.8 & .087 & 12.65 & 4.54 & .070 & 0.29 & 20.94 & 19.54 \\
\hline & & 32 & 4 & 12 & 1.6 & .145 & 25.01 & 8.43 & .134 & 0.12 & 21.84 & 7.59 \\
\hline & & 64 & 8 & 24 & 3.2 & .274 & 50.33 & 16.21 & .277 & 0.01 & 21.36 & -1.09 \\
\hline & & 128 & 16 & 48 & 6.4 & .533 & 98.28 & 29.88 & .538 & 0.03 & 23.22 & -0.94 \\
\hline Mean values & & & & & & .259 & 44.82 & 14.04 & .252 & 0.121 & 25.03 & 6.60 \\
\hline \multirow[t]{12}{*}{ Rule 4} & \multirow[t]{4}{*}{4} & 16 & 2 & 6 & 0.8 & .087 & 11.49 & 3.58 & .073 & 0.20 & 28.19 & 16.09 \\
\hline & & 32 & 4 & 12 & 1.6 & .145 & 22.79 & 7.07 & .134 & 0.12 & 28.78 & 7.59 \\
\hline & & 64 & 8 & 24 & 3.2 & .274 & 45.94 & 13.96 & .261 & 0.17 & 28.22 & 4.74 \\
\hline & & 128 & 16 & 48 & 6.4 & .533 & 91.48 & 26.71 & .534 & 0.00 & 28.53 & -0.19 \\
\hline & \multirow[t]{4}{*}{8} & 16 & 2 & 6 & 0.8 & .087 & 12.31 & 3.99 & .067 & 0.40 & 23.06 & 22.99 \\
\hline & & 32 & 4 & 12 & 1.6 & .145 & 23.85 & 7.36 & .127 & 0.32 & 25.47 & 12.41 \\
\hline & & 64 & 8 & 24 & 3.2 & .274 & 47.68 & 14.39 & .255 & 0.36 & 25.50 & 6.93 \\
\hline & & 128 & 16 & 48 & 6.4 & .533 & 94.46 & 27.23 & .516 & 0.29 & 26.20 & 3.19 \\
\hline & \multirow{4}{*}{12} & 16 & 2 & 6 & 0.8 & .087 & 12.24 & 3.99 & .066 & 0.44 & 23.50 & 24.14 \\
\hline & & 32 & 4 & 12 & 1.6 & .145 & 25.41 & 8.50 & .127 & 0.32 & 20.59 & 12.41 \\
\hline & & 64 & 8 & 24 & 3.2 & .274 & 49.38 & 15.02 & .258 & 0.26 & 22.84 & 5.84 \\
\hline & & 128 & 16 & 48 & 6.4 & .533 & 97.21 & 28.66 & .528 & 0.03 & 24.05 & 0.94 \\
\hline Mean values & & & & & & .259 & 44.52 & 13.37 & .246 & 0.242 & 25.41 & 9.76 \\
\hline
\end{tabular}

Note-The mean squared difference (MSD) is 1,000 times the MSD between the empirical proportion of rejections (EPR) of $\mathrm{H}_{0}($ here, it is an estimation of the correct rejections rate or power) and the power of $N_{\mathrm{FSR}}$. $N_{\text {Efficiency }}$, percentage of savings in number of observations, following Equation 5; $P_{\text {Efficiency }}$, percentage of decrease or loss in power of $N_{\mathrm{FSR}}$, following Equation 6.

mum value for $N$ as a stopping criterion, the maximum value of $p$ for continuing to incorporate subjects while maintaining the Type I error rate at a .05 level was .45 .

Figure 2 shows a graphical representation of the determination of the upper bound for the one-way ANOVA general test and for the two linear contrasts of multiple comparisons among treatment means. As can be seen, the .50 and .45 values were the ones with the smallest MSD values. Furthermore, the subsequent upper bound values obtained higher MSD values. Therefore, in Study 2, the 


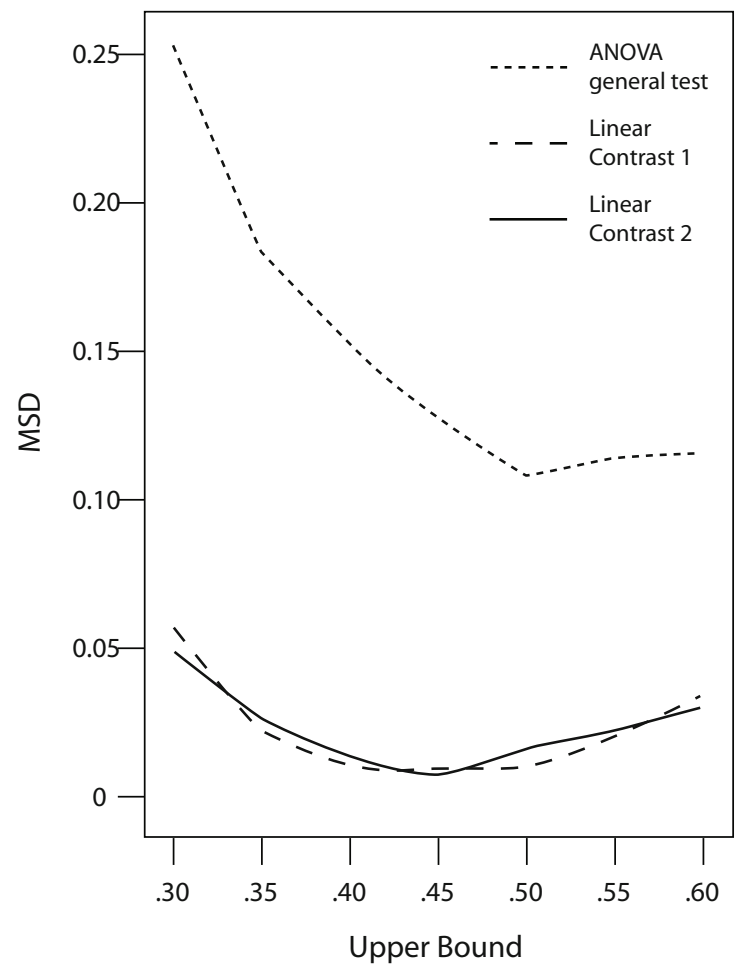

Figure 2. Graphical representation of the determination of the upper bound $\left(\alpha_{u}\right)$ for the uncertainty region that holds the Type I error as close as possible to the significance level for each ANOVA test under study. The mean squared difference (MSD) is 1,000 times the MSD between the empirical proportion of rejections (here, an estimate of the Type I error rate) and the intended alpha level (.05).

upper bound for the general test and for the contrasts was .50 and .45 , respectively.

Study 2: Efficiency of CLAST in terms of sample size and power. Tables $3 \mathrm{~A}$ and $3 \mathrm{~B}$ include some simulations similar to those in Table 2A for the one-way ANOVA general test, but for the case in which $\mathrm{H}_{0}$ is false, with different $v$ values. Both tables are divided into six sections, each showing the mean and standard deviation for the sample size needed with the CLAST rule, the EPR of $\mathrm{H}_{0}$ (here, an estimate of power for CLAST), the corresponding MSD value, and the efficiency of CLAST, as compared with the FSR, in terms of sample size and power for each rule and sample size condition.

The results for $v=.05$ and for $\alpha_{\mathrm{u}}=.50$ indicate that the efficiency achieved by CLAST, as compared with FSR, in terms of sample size for the general one-way ANOVA test was about a $32 \%$ savings in the number of observations, on average, for Rule 1, $8 \%$ for Rule 2, and 25\% for Rules 3 and 5 (see the $N_{\text {Efficiency }}$ column in Table $3 \mathrm{~A}$ ). The efficiency in terms of sample size was especially pronounced for Rule 1. In addition, the results indicate that the EPR was very close to the power of the corresponding FSR for Rules 3 and 4 (see the MSD column in Table 3A). For Rule 1, the EPR was lower than the power of the corre- sponding FSR (see the $P_{\text {Efficiency }}$ column in Table $3 \mathrm{~A}$ ), and for Rule 2, the EPR was higher than the power.

The results for $v=.20$ and for $\alpha_{\mathrm{u}}=.50$ indicate that the efficiency achieved by CLAST, as compared with FSR, in terms of sample size for the general one-way ANOVA test was about a $35 \%$ savings in the number of observations, on average, for Rule 1, 13\% for Rule 2, and $27 \%$ for Rules 3 and 5 (see the $N_{\text {Efficiency }}$ column in Table 3B). Again, the efficiency in terms of sample size was especially pronounced for Rule 1 . In addition, the results indicate that the EPR was very close to the power of the corresponding FSR for Rules 3 and 4 (see the MSD column in Table 3B). The EPR was lower than the power of the corresponding FSR for Rule 1 and higher for Rule 2 (see the $P_{\text {Efficiency }}$ column in Table 3B).

Overall, the results indicate that for the one-way ANOVA general test for fixed effects models, the CLAST rule allows a saving of observations without losing the power associated with $N_{\mathrm{FSR}}$ in all cases except for Rule 1.

The means of $N$ for each value of $N_{\text {added }}$ and the condition $v=.05$ are 44.6 for $N_{\text {added }}=4,46.3$ for $N_{\text {added }}=8$, and 48.0 for $N_{\text {added }}=12$. The means of the EPR for each value of $N_{\text {added }}$ are $.261, .258$, and .262, respectively. The means of $N$ for the condition $v=.2$ are 38.8, 40.0, and 41.1 , and the means of the EPR are .639, .631, and .637. Thus, increasing the value of $N_{\text {added }}$ leads to an increased sample size without substantially improving the power of the test.

Tables 4A and 4B include the results of simulations similar to those in Tables $3 \mathrm{~A}$ and $3 \mathrm{~B}$ for the two linear contrasts of multiple comparisons among treatment means, but for the case in which $\mathrm{H}_{0}$ is false, with different $v$ values.

The results for Linear Contrast 1 with $v=.05$ and $\alpha_{\mathrm{u}}=$ .45 indicate that the efficiency achieved by CLAST, as compared with FSR, in terms of sample size for Linear Contrast 1 was about a $22 \%$ savings in the number of observations, on average, for Rules 2 and 5 and $12 \%$ for Rule 6 (see the $N_{\text {Efficiency }}$ column in Table 4A). The efficiency in terms of sample size was especially pronounced for Rule 6. In addition, the EPR for $\mathrm{H}_{0}$ was very similar to the power found if the FSR was applied with a sample size of $N_{\text {FSR }}$ (see the $P_{\text {Efficiency }}$ column in Table 4A). In this contrast, the efficiency of CLAST in terms of power holds for all the rules for allocating $N_{\text {added }}$ observations to the four groups under study.

The results for Linear Contrast 2 with $v=.12$ and $\alpha_{\mathrm{u}}=.45$ indicate that the efficiency achieved by CLAST, as compared with FSR, in terms of sample size for Linear Contrast 2 was about a 27\% savings in the number of observations, on average, for Rules 5 and 6 and $15 \%$ for Rule 2 (see the $N_{\text {Efficiency }}$ column in Table 4B). In this case, the efficiency in terms of sample size was especially pronounced for Rules 5 and 6 (see the $P_{\text {Efficiency }}$ column in Table 4B). The results of efficiency in terms of power indicate that the EPR was very similar to the power of the corresponding FSR for all the rules.

Overall, the results indicate that for these linear contrasts of multiple comparisons among treatment means for 
Table 3B

Results of Simulations of CLAST With $\alpha_{\mathrm{u}}=.50$ and $v=.20$ in the One-Way ANOVA General Test

\begin{tabular}{|c|c|c|c|c|c|c|c|c|c|c|c|c|}
\hline & $N_{\text {added }}$ & $N_{\text {FSR }}$ & $N 1$ & $N_{\max }$ & $\delta$ & $\begin{array}{c}\text { Power of } \\
N_{\text {FSR }}\end{array}$ & $\begin{array}{c}\text { Mean } \\
\text { of } N\end{array}$ & $\begin{array}{l}\text { Standard } \\
\text { Deviation } \\
\text { of } N\end{array}$ & EPR & MSD & $N_{\text {Efficiency }}$ & $P_{\text {Efficiency }}$ \\
\hline \multirow{12}{*}{ Rule 1} & \multirow[t]{4}{*}{4} & 16 & 2 & 6 & 3.2 & .220 & 10.53 & 1.93 & .144 & 5.78 & 34.19 & 34.55 \\
\hline & & 32 & 4 & 12 & 6.4 & .486 & 23.21 & 5.40 & .422 & 4.10 & 27.47 & 13.17 \\
\hline & & 64 & 8 & 24 & 12.8 & .840 & 43.35 & 10.46 & .812 & 0.78 & 32.27 & 3.33 \\
\hline & & 128 & 16 & 48 & 25.6 & .993 & 69.95 & 11.48 & .982 & 0.12 & 45.35 & 1.11 \\
\hline & \multirow[t]{4}{*}{8} & 16 & 2 & 6 & 3.2 & .220 & 10.55 & 1.92 & .141 & 6.24 & 34.06 & 35.91 \\
\hline & & 32 & 4 & 12 & 6.4 & .486 & 21.77 & 3.59 & .333 & 23.41 & 31.97 & 31.48 \\
\hline & & 64 & 8 & 24 & 12.8 & .840 & 44.42 & 10.15 & .783 & 3.25 & 30.59 & 6.79 \\
\hline & & 128 & 16 & 48 & 25.6 & .993 & 71.10 & 12.38 & .984 & 0.08 & 44.45 & 0.91 \\
\hline & \multirow[t]{4}{*}{12} & 16 & 2 & 6 & 3.2 & .220 & 10.52 & 1.93 & .148 & 5.18 & 34.25 & 32.73 \\
\hline & & 32 & 4 & 12 & 6.4 & .486 & 21.88 & 3.53 & .346 & 19.60 & 31.63 & 28.81 \\
\hline & & 64 & 8 & 24 & 12.8 & .840 & 47.31 & 12.32 & .827 & 0.17 & 26.08 & 1.55 \\
\hline & & 128 & 16 & 48 & 25.6 & .993 & 72.45 & 13.91 & .986 & 0.05 & 43.40 & 0.70 \\
\hline Mean values & & & & & & .635 & 37.25 & 7.42 & .576 & 5.73 & 34.64 & 15.92 \\
\hline \multirow{12}{*}{ Rule 2} & \multirow[t]{4}{*}{4} & 16 & 2 & 6 & 3.2 & .220 & 15.94 & 7.10 & .310 & 8.10 & 0.38 & -40.91 \\
\hline & & 32 & 4 & 12 & 6.4 & .486 & 31.07 & 12.92 & .612 & 15.88 & 2.91 & -25.93 \\
\hline & & 64 & 8 & 24 & 12.8 & .840 & 49.90 & 19.53 & .884 & 1.94 & 22.03 & -5.24 \\
\hline & & 128 & 16 & 48 & 25.6 & .993 & 72.30 & 16.51 & .990 & 0.01 & 43.52 & 0.30 \\
\hline & \multirow[t]{4}{*}{8} & 16 & 2 & 6 & 3.2 & .220 & 17.14 & 7.32 & .314 & 8.84 & -7.13 & -42.73 \\
\hline & & 32 & 4 & 12 & 6.4 & .486 & 33.18 & 13.30 & .606 & 14.40 & -3.69 & -24.69 \\
\hline & & 64 & 8 & 24 & 12.8 & .840 & 52.65 & 20.68 & .897 & 3.25 & 17.73 & -6.79 \\
\hline & & 128 & 16 & 48 & 25.6 & .993 & 73.74 & 18.27 & .990 & 0.01 & 42.39 & 0.30 \\
\hline & \multirow[t]{4}{*}{12} & 16 & 2 & 6 & 3.2 & .220 & 17.52 & 7.36 & .299 & 6.24 & -9.50 & -35.91 \\
\hline & & 32 & 4 & 12 & 6.4 & .486 & 34.61 & 13.27 & .618 & 17.42 & -8.16 & -27.16 \\
\hline & & 64 & 8 & 24 & 12.8 & .840 & 54.74 & 21.36 & .903 & 3.97 & 14.47 & -7.50 \\
\hline & & 128 & 16 & 48 & 25.6 & .993 & 74.57 & 19.18 & .990 & 0.01 & 41.74 & 0.30 \\
\hline Mean values & & & & & & .635 & 43.95 & 14.73 & .701 & 6.67 & 13.06 & -18.00 \\
\hline \multirow[t]{12}{*}{ Rule 3} & \multirow[t]{4}{*}{4} & 16 & 2 & 6 & 3.2 & .220 & 12.53 & 3.93 & .214 & 0.04 & 21.69 & 2.73 \\
\hline & & 32 & 4 & 12 & 6.4 & .486 & 25.35 & 7.25 & .496 & 0.10 & 20.78 & -2.06 \\
\hline & & 64 & 8 & 24 & 12.8 & .840 & 44.40 & 12.38 & .842 & 0.00 & 30.63 & -0.24 \\
\hline & & 128 & 16 & 48 & 25.6 & .993 & 70.12 & 11.98 & .990 & 0.01 & 45.22 & 0.30 \\
\hline & \multirow[t]{4}{*}{8} & 16 & 2 & 6 & 3.2 & .220 & 12.92 & 4.05 & .209 & 0.12 & 19.25 & 5.00 \\
\hline & & 32 & 4 & 12 & 6.4 & .486 & 26.87 & 7.74 & .499 & 0.17 & 16.03 & -2.67 \\
\hline & & 64 & 8 & 24 & 12.8 & .840 & 46.78 & 13.44 & .846 & 0.04 & 26.91 & -0.71 \\
\hline & & 128 & 16 & 48 & 25.6 & .993 & 71.46 & 13.56 & .988 & 0.03 & 44.17 & 0.50 \\
\hline & \multirow[t]{4}{*}{12} & 16 & 2 & 6 & 3.2 & .220 & 13.64 & 4.42 & .209 & 0.12 & 14.75 & 5.00 \\
\hline & & 32 & 4 & 12 & 6.4 & .486 & 27.49 & 8.00 & .501 & 0.23 & 14.09 & -3.09 \\
\hline & & 64 & 8 & 24 & 12.8 & .840 & 48.80 & 14.04 & .851 & 0.12 & 23.75 & -1.31 \\
\hline & & 128 & 16 & 48 & 25.6 & .993 & 72.44 & 14.58 & .989 & 0.02 & 43.41 & 0.40 \\
\hline Mean values & & & & & & .635 & 39.40 & 9.61 & .636 & 0.082 & 26.72 & 0.32 \\
\hline \multirow[t]{12}{*}{ Rule 4} & \multirow[t]{4}{*}{4} & 16 & 2 & 6 & 3.2 & .220 & 12.49 & 3.71 & .210 & 0.10 & 21.94 & 4.55 \\
\hline & & 32 & 4 & 12 & 6.4 & .486 & 25.12 & 6.94 & .487 & 0.00 & 21.50 & -0.21 \\
\hline & & 64 & 8 & 24 & 12.8 & .840 & 44.52 & 12.07 & .836 & 0.02 & 30.44 & 0.48 \\
\hline & & 128 & 16 & 48 & 25.6 & .993 & 70.12 & 11.89 & .986 & 0.05 & 45.22 & 0.70 \\
\hline & \multirow[t]{4}{*}{8} & 16 & 2 & 6 & 3.2 & .220 & 13.06 & 3.86 & .193 & 0.73 & 18.37 & 12.27 \\
\hline & & 32 & 4 & 12 & 6.4 & .486 & 26.31 & 7.04 & .484 & 0.00 & 17.78 & 0.41 \\
\hline & & 64 & 8 & 24 & 12.8 & .840 & 46.36 & 12.71 & .836 & 0.02 & 27.56 & 0.48 \\
\hline & & 128 & 16 & 48 & 25.6 & .993 & 71.21 & 13.17 & .990 & 0.01 & 44.37 & 0.30 \\
\hline & \multirow[t]{4}{*}{12} & 16 & 2 & 6 & 3.2 & .220 & 13.07 & 3.86 & .197 & 0.53 & 18.31 & 10.45 \\
\hline & & 32 & 4 & 12 & 6.4 & .486 & 27.70 & 7.88 & .498 & 0.14 & 13.44 & -2.47 \\
\hline & & 64 & 8 & 24 & 12.8 & .840 & 47.83 & 13.15 & .842 & 0.00 & 25.27 & -0.24 \\
\hline & & 128 & 16 & 48 & 25.6 & .993 & 72.35 & 14.55 & .989 & 0.02 & 43.48 & 0.40 \\
\hline Mean values & & & & & & .635 & 39.18 & 9.24 & .629 & 0.135 & 27.31 & 2.26 \\
\hline
\end{tabular}

Note-The mean squared difference (MSD) is 1,000 times the MSD between the empirical proportion of rejections (EPR) of $\mathrm{H}_{0}($ here, it is an estimation of the correct rejections rate or power) and the power of $N_{\mathrm{FSR}} . N_{\text {Efficiency }}$, percentage of savings in number of observations, following Equation 5; $P_{\text {Efficiency }}$, percentage of decrease or loss in power of $N_{\mathrm{FSR}}$, following Equation 6.

one-way ANOVA fixed effects models, the CLAST rule allowed a saving of observations without losing the power associated with $N_{\mathrm{FSR}}$ in all cases and with all the rules for allocating $N_{\text {added }}$ observations to the four groups.
For Linear Contrast 1 , the means of $N$ as a function of $N_{\text {added }}$ are 46.5, 49.6, and 51.6, and the means of EPR were $.411, .415$, and .420 . For Linear Contrast 2, the means of $N$ are 41.0, 40.6, and 42.8, and the means of EPR were .655, 
Table 4A

Results of Simulations of CLAST With $\alpha_{\mathrm{u}}=.45$ and $v=.05$ in the Linear Contrast 1

\begin{tabular}{|c|c|c|c|c|c|c|c|c|c|c|c|c|}
\hline & $N_{\text {added }}$ & $N_{\mathrm{FSR}}$ & $N 1$ & $N_{\max }$ & $\delta$ & $\begin{array}{c}\text { Power of } \\
N_{\mathrm{FSR}} \\
\end{array}$ & $\begin{array}{l}\text { Mean } \\
\text { of } N\end{array}$ & $\begin{array}{l}\text { Standard } \\
\text { Deviation } \\
\text { of } N \\
\end{array}$ & EPR & MSD & $N_{\text {Efficiency }}$ & $P_{\text {Efficiency }}$ \\
\hline \multirow{12}{*}{ Rule 2} & \multirow{4}{*}{4} & 16 & 2 & 6 & 0.8 & .131 & 13.74 & 6.72 & .160 & 0.84 & 14.12 & -21.76 \\
\hline & & 32 & 4 & 12 & 1.6 & .231 & 27.52 & 13.32 & .272 & 1.68 & 14.00 & -17.92 \\
\hline & & 64 & 8 & 24 & 3.2 & .421 & 54.74 & 25.36 & .484 & 3.97 & 14.47 & -14.99 \\
\hline & & 128 & 16 & 48 & 6.4 & .709 & 100.49 & 43.53 & .754 & 2.03 & 21.49 & -6.28 \\
\hline & \multirow[t]{4}{*}{8} & 16 & 2 & 6 & 0.8 & .131 & 14.86 & 7.23 & .154 & 0.53 & 7.11 & -17.48 \\
\hline & & 32 & 4 & 12 & 1.6 & .231 & 29.47 & 13.92 & .273 & 1.76 & 7.90 & -18.10 \\
\hline & & 64 & 8 & 24 & 3.2 & .421 & 57.71 & 26.27 & .487 & 4.36 & 9.82 & -15.72 \\
\hline & & 128 & 16 & 48 & 6.4 & .709 & 103.12 & 44.34 & .758 & 2.40 & 19.43 & -6.87 \\
\hline & \multirow[t]{4}{*}{12} & 16 & 2 & 6 & 0.8 & .131 & 15.47 & 7.46 & .158 & 0.73 & 3.32 & -20.46 \\
\hline & & 32 & 4 & 12 & 1.6 & .231 & 30.62 & 14.19 & .280 & 2.40 & 4.31 & -21.21 \\
\hline & & 64 & 8 & 24 & 3.2 & .421 & 59.26 & 26.71 & .489 & 4.62 & 7.40 & -16.20 \\
\hline & & 128 & 16 & 48 & 6.4 & .709 & 106.22 & 45.97 & .759 & 2.50 & 17.01 & -7.07 \\
\hline Mean values & & & & & & .373 & 51.10 & 22.92 & .419 & 2.32 & 11.70 & -15.34 \\
\hline \multirow[t]{12}{*}{ Rule 5} & \multirow[t]{4}{*}{4} & 16 & 2 & 6 & 0.8 & .131 & 13.64 & 6.69 & .163 & 1.02 & 14.77 & -24.43 \\
\hline & & 32 & 4 & 12 & 1.6 & .231 & 27.73 & 13.36 & .281 & 2.50 & 13.33 & -21.47 \\
\hline & & 64 & 8 & 24 & 3.2 & .421 & 55.24 & 25.43 & .488 & 4.49 & 13.69 & -15.82 \\
\hline & & 128 & 16 & 48 & 6.4 & .709 & 99.96 & 43.03 & .755 & 2.12 & 21.91 & -6.52 \\
\hline & \multirow[t]{4}{*}{8} & 16 & 2 & 6 & 0.8 & .131 & 14.88 & 7.26 & .158 & 0.73 & 6.98 & -20.99 \\
\hline & & 32 & 4 & 12 & 1.6 & .231 & 29.21 & 13.91 & .276 & 2.03 & 8.72 & -19.39 \\
\hline & & 64 & 8 & 24 & 3.2 & .421 & 57.70 & 26.24 & .484 & 3.97 & 9.84 & -14.87 \\
\hline & & 128 & 16 & 48 & 6.4 & .709 & 104.22 & 45.43 & .752 & 1.85 & 18.57 & -6.02 \\
\hline & \multirow[t]{4}{*}{12} & 16 & 2 & 6 & 0.8 & .131 & 15.52 & 7.45 & .157 & 0.68 & 2.98 & -19.47 \\
\hline & & 32 & 4 & 12 & 1.6 & .231 & 30.46 & 14.28 & .281 & 2.50 & 4.83 & -21.86 \\
\hline & & 64 & 8 & 24 & 3.2 & .421 & 59.80 & 27.00 & .494 & 5.33 & 6.56 & -17.41 \\
\hline & & 128 & 16 & 48 & 6.4 & .709 & 106.05 & 45.81 & .763 & 2.92 & 17.15 & -7.67 \\
\hline Mean values & & & & & & .373 & 51.20 & 22.99 & .421 & 2.51 & 11.61 & -16.33 \\
\hline \multirow[t]{12}{*}{ Rule 6} & \multirow[t]{4}{*}{4} & 16 & 2 & 6 & 0.8 & .131 & 11.45 & 3.63 & .142 & 0.12 & 28.44 & -8.09 \\
\hline & & 32 & 4 & 12 & 1.6 & .231 & 22.79 & 7.09 & .247 & 0.26 & 28.80 & -6.71 \\
\hline & & 64 & 8 & 24 & 3.2 & .421 & 45.48 & 13.60 & .454 & 1.09 & 28.93 & -7.77 \\
\hline & & 128 & 16 & 48 & 6.4 & .709 & 85.51 & 24.04 & .735 & 0.68 & 33.19 & -3.68 \\
\hline & \multirow[t]{4}{*}{8} & 16 & 2 & 6 & 0.8 & .131 & 13.54 & 5.50 & .153 & 0.48 & 15.38 & -16.87 \\
\hline & & 32 & 4 & 12 & 1.6 & .231 & 25.94 & 9.85 & .265 & 1.16 & 18.95 & -14.76 \\
\hline & & 64 & 8 & 24 & 3.2 & .421 & 51.23 & 18.75 & .470 & 2.40 & 19.95 & -11.69 \\
\hline & & 128 & 16 & 48 & 6.4 & .709 & 93.61 & 31.85 & .749 & 1.60 & 26.87 & -5.63 \\
\hline & \multirow[t]{4}{*}{12} & 16 & 2 & 6 & 0.8 & .131 & 14.12 & 6.00 & .153 & 0.48 & 11.74 & -16.87 \\
\hline & & 32 & 4 & 12 & 1.6 & .231 & 27.83 & 11.06 & .269 & 1.44 & 13.04 & -16.62 \\
\hline & & 64 & 8 & 24 & 3.2 & .421 & 54.47 & 20.72 & .475 & 2.92 & 14.90 & -12.87 \\
\hline & & 128 & 16 & 48 & 6.4 & .709 & 99.23 & 36.10 & .760 & 2.60 & 22.48 & -7.22 \\
\hline Mean values & & & & & & .373 & 45.43 & 15.68 & .406 & 1.27 & 21.89 & -10.73 \\
\hline
\end{tabular}

Note-The mean squared difference (MSD) is 1,000 times the MSD between the empirical proportion of rejections (EPR) of $\mathrm{H}_{0}($ here, it is an estimation of the correct rejections rate or power) and the power of $N_{\mathrm{FSR}}$. $N_{\text {Efficiency, }}$ percentage of savings in number of observations, following Equation 5; $P_{\text {Efficiency }}$, percentage of decrease or loss in power of $N_{\mathrm{FSR}}$, following Equation 6.

.643 , and .655. As with the results for the general ANOVA condition, increasing $N_{\text {added }}$ produced a small increase of $N$ but did not alter the power of the test too much.

Table 5 shows the precision of the estimates of $\mu_{j}$ under the four rules. The columns labeled $n_{1}$ to $n_{4}$ contain the mean number of observations assigned to each group at the end of the sequential procedure. They are inversely related to the precision of the estimate, because the standard error of the sample mean is $\sigma / \sqrt{ } n_{j}$. The columns labeled RMSD to $\mathrm{RMSD}_{4}$ include the mean of the root-mean squared difference for the estimate of $\mu_{j}$. Suppose that $\bar{Y}_{j}^{(k)}$ is the sample mean for group $j$ at the end of the $k$ replication of the procedure. Since there are 10,000 replications for each condition, the $\mathrm{RMSD}_{j}$ value is given by

$$
\operatorname{RMSD}_{j}=\sqrt{\frac{\sum_{k=1}^{10,000}\left(\bar{Y}_{j}^{(k)}-\mu_{j}\right)^{2}}{10,000}} .
$$

As is shown in Table 5, the precision of the estimates in the one-way ANOVA general test was lower with Rule 1 than with any other rule, because the sample size was smaller. On the contrary, Rule 2 was the most precise, because it required larger samples than did the others to reach a decision. Rules 3 and 4 allocated more observations at the extreme groups than at the middle ones; however, precision was smaller than with Rule 2 , because of the sample sizes. 
Table 4B

Results of Simulations of CLAST With $\alpha_{\mathrm{u}}=.45$ and $v=.12$ in the Linear Contrast 2

\begin{tabular}{|c|c|c|c|c|c|c|c|c|c|c|c|c|}
\hline & $N_{\text {added }}$ & $N_{\mathrm{FSR}}$ & $N 1$ & $N_{\max }$ & $\delta$ & $\begin{array}{c}\text { Power of } \\
N_{\text {FSR }}\end{array}$ & $\begin{array}{c}\text { Mean } \\
\text { of } N\end{array}$ & $\begin{array}{l}\text { Standard } \\
\text { Deviation } \\
\text { of } N\end{array}$ & EPR & MSD & $N_{\text {Efficiency }}$ & $P_{\text {Efficiency }}$ \\
\hline \multirow[t]{12}{*}{ Rule 2} & \multirow[t]{4}{*}{4} & 16 & 2 & 6 & 1.92 & .248 & 14.98 & 7.00 & .314 & 4.36 & 6.35 & -26.53 \\
\hline & & 32 & 4 & 12 & 3.84 & .473 & 29.30 & 12.96 & .561 & 7.74 & 8.42 & -18.67 \\
\hline & & 64 & 8 & 24 & 7.68 & .778 & 50.45 & 21.19 & .819 & 1.68 & 21.17 & -5.31 \\
\hline & & 128 & 16 & 48 & 15.36 & .973 & 77.15 & 23.06 & .967 & 0.04 & 39.72 & 0.62 \\
\hline & \multirow[t]{4}{*}{8} & 16 & 2 & 6 & 1.92 & .248 & 16.25 & 7.36 & .317 & 4.76 & -1.57 & -27.98 \\
\hline & & 32 & 4 & 12 & 3.84 & .473 & 30.97 & 13.48 & .557 & 7.06 & 3.21 & -17.80 \\
\hline & & 64 & 8 & 24 & 7.68 & .778 & 52.89 & 22.05 & .830 & 2.70 & 17.36 & -6.74 \\
\hline & & 128 & 16 & 48 & 15.36 & .973 & 78.69 & 24.32 & .970 & 0.01 & 38.52 & 0.33 \\
\hline & \multirow[t]{4}{*}{12} & 16 & 2 & 6 & 1.92 & .248 & 16.77 & 7.41 & .307 & 3.48 & -4.80 & -23.59 \\
\hline & & 32 & 4 & 12 & 3.84 & .473 & 32.48 & 13.71 & .560 & 7.57 & -1.50 & -18.37 \\
\hline & & 64 & 8 & 24 & 7.68 & .778 & 54.85 & 22.86 & .834 & 3.14 & 14.30 & -7.26 \\
\hline & & 128 & 16 & 48 & 15.36 & .973 & 79.90 & 25.64 & .973 & 0.00 & 37.58 & 0.05 \\
\hline Mean values & & & & & & .618 & 44.56 & 16.75 & .667 & 3.54 & 14.90 & -12.60 \\
\hline \multirow[t]{12}{*}{ Rule 5} & \multirow[t]{4}{*}{4} & 16 & 2 & 6 & 1.92 & .248 & 13.22 & 4.62 & .288 & 1.60 & 17.40 & -16.33 \\
\hline & & 32 & 4 & 12 & 3.84 & .473 & 25.88 & 8.61 & .529 & 3.14 & 19.12 & -11.75 \\
\hline & & 64 & 8 & 24 & 7.68 & .778 & 46.35 & 14.87 & .804 & 0.68 & 27.58 & -3.34 \\
\hline & & 128 & 16 & 48 & 15.36 & .973 & 74.73 & 17.93 & .968 & 0.03 & 41.62 & 0.48 \\
\hline & \multirow[t]{4}{*}{8} & 16 & 2 & 6 & 1.92 & .248 & 12.12 & 3.45 & .253 & 0.03 & 24.26 & -1.85 \\
\hline & & 32 & 4 & 12 & 3.84 & .473 & 24.12 & 6.29 & .498 & 0.63 & 24.63 & -5.31 \\
\hline & & 64 & 8 & 24 & 7.68 & .778 & 44.28 & 11.27 & .799 & 0.44 & 30.82 & -2.72 \\
\hline & & 128 & 16 & 48 & 15.36 & .973 & 73.27 & 14.68 & .969 & 0.02 & 42.76 & 0.44 \\
\hline & \multirow[t]{4}{*}{12} & 16 & 2 & 6 & 1.92 & .248 & 13.88 & 4.92 & .285 & 1.37 & 13.26 & -15.12 \\
\hline & & 32 & 4 & 12 & 3.84 & .473 & 27.60 & 8.74 & .538 & 4.23 & 13.74 & -13.70 \\
\hline & & 64 & 8 & 24 & 7.68 & .778 & 47.68 & 13.73 & .808 & 0.90 & 25.50 & -3.87 \\
\hline & & 128 & 16 & 48 & 15.36 & .973 & 75.56 & 17.63 & .971 & 0.00 & 40.97 & 0.18 \\
\hline Mean values & & & & & & .618 & 39.89 & 10.56 & .643 & 1.09 & 26.81 & -6.07 \\
\hline \multirow[t]{12}{*}{ Rule 6} & \multirow[t]{4}{*}{4} & 16 & 2 & 6 & 1.92 & .248 & 13.33 & 4.61 & .300 & 2.70 & 16.68 & -20.81 \\
\hline & & 32 & 4 & 12 & 3.84 & .473 & 26.01 & 8.66 & .531 & 3.36 & 18.72 & -12.30 \\
\hline & & 64 & 8 & 24 & 7.68 & .778 & 46.29 & 14.81 & .811 & 1.09 & 27.67 & -4.28 \\
\hline & & 128 & 16 & 48 & 15.36 & .973 & 74.45 & 17.54 & .970 & 0.01 & 41.84 & 0.33 \\
\hline & \multirow[t]{4}{*}{8} & 16 & 2 & 6 & 1.92 & .248 & 12.08 & 3.45 & .256 & 0.06 & 24.52 & -3.10 \\
\hline & & 32 & 4 & 12 & 3.84 & .473 & 24.08 & 6.31 & .501 & 0.78 & 24.77 & -6.00 \\
\hline & & 64 & 8 & 24 & 7.68 & .778 & 44.27 & 11.39 & .793 & 0.23 & 30.82 & -1.90 \\
\hline & & 128 & 16 & 48 & 15.36 & .973 & 73.64 & 14.93 & .968 & 0.03 & 42.47 & 0.47 \\
\hline & \multirow[t]{4}{*}{12} & 16 & 2 & 6 & 1.92 & .248 & 13.90 & 4.92 & .286 & 1.44 & 13.14 & -15.44 \\
\hline & & 32 & 4 & 12 & 3.84 & .473 & 27.57 & 8.79 & .523 & 2.50 & 13.83 & -10.57 \\
\hline & & 64 & 8 & 24 & 7.68 & .778 & 47.53 & 13.65 & .807 & 0.84 & 25.74 & -3.77 \\
\hline & & 128 & 16 & 48 & 15.36 & .973 & 75.77 & 17.68 & .972 & 0.00 & 40.80 & 0.12 \\
\hline Mean values & & & & & & .618 & 39.91 & 10.56 & .643 & 1.09 & 26.75 & -6.44 \\
\hline
\end{tabular}

Note-The mean squared difference (MSD) is 1,000 times the MSD between the empirical proportion of rejections (EPR) of $\mathrm{H}_{0}$ (here, it is an estimation of the correct rejections rate or power) and the power of $N_{\mathrm{FSR}} \cdot N_{\mathrm{Efficiency}}$, percentage of savings in number of observations, following Equation $5 ; P_{\text {Efficiency }}$, percentage of decrease or loss in power of $N_{\mathrm{FSR}}$, following Equation 6.

Table 5 also shows the precision of the estimates of $\mu_{j}$ and $L$ under the three rules for the linear contrasts considered in the study, where $L$ is

$$
\sum_{j} c_{j} \mu_{j}
$$

The true value of $L$ was 2 for Linear Contrast 1 and 2.4 for Linear Contrast 2. The RMSD for $L$ (denoted by $\mathrm{RMSD}_{L}$ ) was computed as described above for $\mathrm{RMSD}_{j}$. As can be seen, Rule 2 was the most imprecise for estimating $L$, Rule 6 was the most precise for Contrast 1, and Rule 5 was the most precise for Contrast 2. In contrast to the general null hypothesis, Rule 2 leads to smaller samples sizes than do the other rules.

\section{DISCUSSION}

In the present study, the efficiency of the CLAST sequential rule in terms of sample size and power for the one-way ANOVA general test for fixed effects models and for two linear contrasts of multiple comparisons among treatment means is shown. Sequential stopping rules are an alternative to the FSR, in which the sample size is determined in advance. Several studies have shown that determining the sample size by using sequential rules, in which the number of observations is not fixed in advance, is more efficient than is using the FSR and that it reflects more realistically the practice of experimental researchers. 
Table 5

Precision of the Estimates

\begin{tabular}{|c|c|c|c|c|c|c|c|c|c|c|c|}
\hline $\mathrm{H}_{0}$ & $v$ & Rule & $n_{1}$ & $n_{2}$ & $n_{3}$ & $n_{4}$ & $\mathrm{RMSD}_{1}$ & $\mathrm{RMSD}_{2}$ & $\mathrm{RMSD}_{3}$ & $\mathrm{RMSD}_{4}$ & $\mathrm{RMSD}_{L}$ \\
\hline \multirow[t]{8}{*}{ General } & .05 & 1 & 11.54 & 9.31 & 9.31 & 11.54 & .174 & .172 & .172 & .173 & \\
\hline & & 2 & 13.56 & 13.56 & 13.56 & 13.56 & .142 & .131 & .132 & .143 & \\
\hline & & 3 & 12.29 & 10.11 & 10.14 & 12.29 & .150 & .137 & .137 & .150 & \\
\hline & & 4 & 12.25 & 10.01 & 9.98 & 12.28 & .153 & .142 & .141 & .152 & \\
\hline & .20 & 1 & 10.40 & 8.23 & 8.24 & 10.39 & .184 & .192 & .192 & .184 & \\
\hline & & 2 & 10.99 & 10.99 & 10.99 & 10.99 & .153 & .139 & .138 & .153 & \\
\hline & & 3 & 10.85 & 8.85 & 8.85 & 10.86 & .167 & .152 & .153 & .168 & \\
\hline & & 4 & 10.86 & 8.73 & 8.73 & 10.85 & .173 & .158 & .157 & .172 & \\
\hline \multirow[t]{3}{*}{ LC 1} & .05 & 2 & 12.78 & 12.78 & 12.78 & 12.78 & .160 & .160 & .160 & .160 & 3.185 \\
\hline & & 5 & 12.80 & 12.80 & 12.80 & 12.80 & .160 & .161 & .163 & .160 & 3.176 \\
\hline & & 6 & 13.56 & 9.26 & 9.26 & 13.46 & .155 & .197 & .198 & .155 & 3.122 \\
\hline \multirow[t]{3}{*}{ LC 2} & .12 & 2 & 11.14 & 11.14 & 11.14 & 11.14 & .179 & .156 & .159 & .156 & 2.236 \\
\hline & & 5 & 12.16 & 9.24 & 9.24 & 9.24 & .166 & .182 & .182 & .179 & 2.146 \\
\hline & & 6 & 12.17 & 9.25 & 9.25 & 9.25 & .166 & .179 & .182 & .181 & 2.150 \\
\hline
\end{tabular}

Note-LC, linear contrast; RMSD, root-mean squared difference.

CLAST is a sequential-stopping rule that establishes not only an initial sample size (N1) to start the process, but also a maximum sample size $\left(N_{\max }\right)$, which is determined by the researcher in advance. Both sample sizes are computed on the basis of the $N$ assumed by the FSR (denoted here by $N_{\mathrm{FSR}}$ ). $N 1$ is half the $N_{\mathrm{FSR}} / J$, and $N_{\max }$ is 1.5 times the $N_{\mathrm{FSR}} / J$. In addition, the CLAST rule establishes that the optimal values of the upper bound of the uncertainty region (denoted here by $\alpha_{\mathrm{u}}$, the $p$ value for each contrast that holds the Type I error rate at the intended level) should be computed for each statistical test. The efficiency of CLAST in terms of sample size and power was demonstrated in previous research for the $t$ test of mean differences with two matched samples and for the chisquare independence test for twofold contingency tables (see Botella et al., 2006) but has not been examined for multiple group statistical tests. The study of the efficiency of the CLAST rule in one-way ANOVA tests presents the additional difficulty of how to allocate the new observations (denoted here by $N_{\text {added }}$ ) to each group. Here, we have proposed six rules for allocating $N_{\text {added }}$ observations in $J$ groups. The $N_{\text {added }}$ observations are incorporated into the sample by groups at each step of the process.

We conducted two simulation studies to determine the optimal value of $\alpha_{\mathrm{u}}$ that holds the Type I error rate at .05 for each statistical test and to evaluate the efficiency of the CLAST rule, as compared with the FSR, in terms of savings in number of observations and in terms of power. The results for the one-way ANOVA general test indicate that the upper bound of the uncertainty region that holds the Type I error rate at .05 is $\alpha_{\mathrm{u}}=.50$. In addition, the CLAST rule allows a saving in number of observations without losing the power associated with $N_{\text {FSR }}$ in all cases except for Rule 1 . That is, when the $N_{\text {added }}$ observations go to the group with the largest estimated effect, it achieves the largest efficiency in terms of sample size, but the power of CLAST is lower than that associated with the FSR. On the contrary, Rule 2 (i.e., when the $N_{\text {added }}$ observations are uniformly assigned to each group) obtains the highest EPR with $\mathrm{H}_{0}$ true or false; however, samples tend to be large.
The results for the linear contrasts indicate that the upper bound of the uncertainty region that holds the Type I error rate at .05 is $\alpha_{\mathrm{u}}=.45$. Furthermore, the CLAST rule allows a saving in number of observations without losing the power associated with $N_{\mathrm{FSR}}$ in all the examined rules and conditions. As in the ANOVA general test, Rule 2 (uniform) gives the highest $\mathrm{EPR}$ with $\mathrm{H}_{0}$ true or false, but the samples are larger than those with the other rules. In addition, Rule 6 (i.e., when the number of $N_{\text {added }}$ observations that go to each group is proportional to the absolute value of its coefficient) is the most efficient in terms of sample size.

In general, the results are somewhat different for each rule. Rule 2 produces large samples, with high precision in parameter estimates, high Type I error rate (similar to the intended one), and high power. Thus, this rule should be used preferably when the cost of adding observations to the sample is small. On the other extreme, Rule 1 produces small samples at the cost of increased errors in parameter estimation and lower power than with other rules. Therefore, Rule 1 seems appropriate for situations in which sampling is very expensive. Rules 3 and 4 produce results intermediate between those found for Rules 1 and 2. They are efficient in terms of $N$ (produce smaller samples than Rule 2), but the power is a bit smaller. Rules 5 and 6 are specific for testing linear contrasts. Rule 6 is the most efficient in terms of $N$, and Rule 2 is the least efficient. The performance of Rule 5 depends on the type of linear contrast. With Linear Contrast 1, Rule 5 is similar to Rule 2 in terms of $N$, and with Linear Contrast 2, it is similar to Rule 6 . Regarding power, Rule 6 has less power than do Rules 2 and 5 for Linear Contrast 1, and the three rules have similar power for Linear Contrast 2.

Overall, our results coincide with those obtained in previous research for the $t$ test of mean differences with two matched samples and for the chi-square independence test for twofold contingency tables, if we compare the CLAST rule with the FSR regarding efficiency in terms of sample size and power. Therefore, the CLAST sequential rule has clear practical advantages in experimental data analyses that involve hypothesis testing with one-way ANOVA 
tests for fixed effects models. One important advantage is that CLAST allows a saving in number of observations, and as a consequence, it reduces the cost of the experiment. Second, CLAST mimics the actual practice of experimental researchers, who do not always adhere strictly to the postulates of the FSR (set the sample size before the data collection, in order to obtain an intended power). In practice, investigators are willing to add more observations to the sample if the results are close to significance or to stop the experiment earlier if the results are unlikely to be significant. CLAST provides explicit guidelines for this kind of practice.

More research should be done to continue developing and testing sequential-sampling rules, such as CLAST, and to assess their efficiency for a wide range of statistical tests. Lastly, but not least important, more effort is also needed to make experimental researchers aware that sequential rules may improve the design of their experiments.

\section{AUTHOR NOTE}

This work was partially supported by Grant $06 / \mathrm{HSE} / 0005 / 2004$ from the Comunidad de Madrid (Spain). Correspondence concerning this article should be addressed to C. Ximénez, Departamento de Psicología Social y Metodología, Universidad Autónoma de Madrid, 28049 Madrid, Spain (e-mail: carmen.ximenez@uam.es).

\section{REFERENCES}

Becker, R. A., Chambers, J. M., \& Wilks, A. R. (1988). The new $S$ language: A programming environment for data analysis and graphics. Pacific Grove, CA: Wadsworth \& Brooks/Cole.

Botella, J., Ximénez, C., Revuelta, J., \& Suero, M. (2006). Optimization of sample size in controlled experiments: The CLAST rule. Behavior Research Methods, 38, 65-76.
EDWARDS, L. K. (1993). Applied analysis of variance in behavioral science. New York: Dekker.

Fiske, D. W., \& JonES, L. V. (1954). Sequential analysis in psychological research. Psychological Bulletin, 51, 264-275.

FRICK, R. W. (1998). A better stopping rule for conventional statistical tests. Behavior Research Methods, Instruments, \& Computers, $\mathbf{3 0}$, 690-697.

GHosh, B. K., \& SEN, P. K. (1991). Handbook of sequential analysis. New York: Dekker.

Jennison, C., \& Turnbull, B. W. (2000). Group sequential methods with applications to clinical trials. Boca Raton, FL: Chapman \& Hall.

JoHnson, N. L. (1953). Some notes on the application of sequential methods in the analysis of variance. Annals of Mathematical Statistics, 24, 614-623.

Kimball, A. W. (1950). Sequential sampling plans for use in psychological test work. Psychometrika, 15, 1-15.

Lan, K. K. G., \& DeMets, D. L. (1989). Changing frequency of interim analysis sequential monitoring. Biometrics, 45, 1017-1020.

O'Brien, P. C., \& Fleming, T. R. (1979). A multiple testing procedure for clinical trials. Biometrics, 35, 549-556.

O’Brien, R. G., \& Muller, K. E. (1993). A unified approach to statistical power for $t$-tests to multivariate models. In L. K. Edwards (Ed.), Applied analysis of variance in behavioral science (pp. 297-344). New York: Dekker.

RAY, W. D. (1956). Sequential analysis applied to certain experimental designs in the analysis of variance. Biometrika, 43, 388-403.

SIEGMUND, D. (1985). Sequential analysis: Tests and confidence intervals. New York: Springer.

Venables, W. N., \& Smith, D. M. (2001). An introduction to R. Available from www.r-project.org/.

WALD, W. (1947). Sequential analysis. New York: Dover.

Wetherill, G. B., \& GlazebrooK, K. D. (1986). Sequential methods in statistics. London: Chapman \& Hall.

(Manuscript received October 18, 2005; revision accepted for publication December 20, 2005.) 